\title{
Second Annual Progress Report on Radiation Tolerance of Controlled Fusion Welds in High Temperature Oxidation Resistant FeCrAl Alloys
}

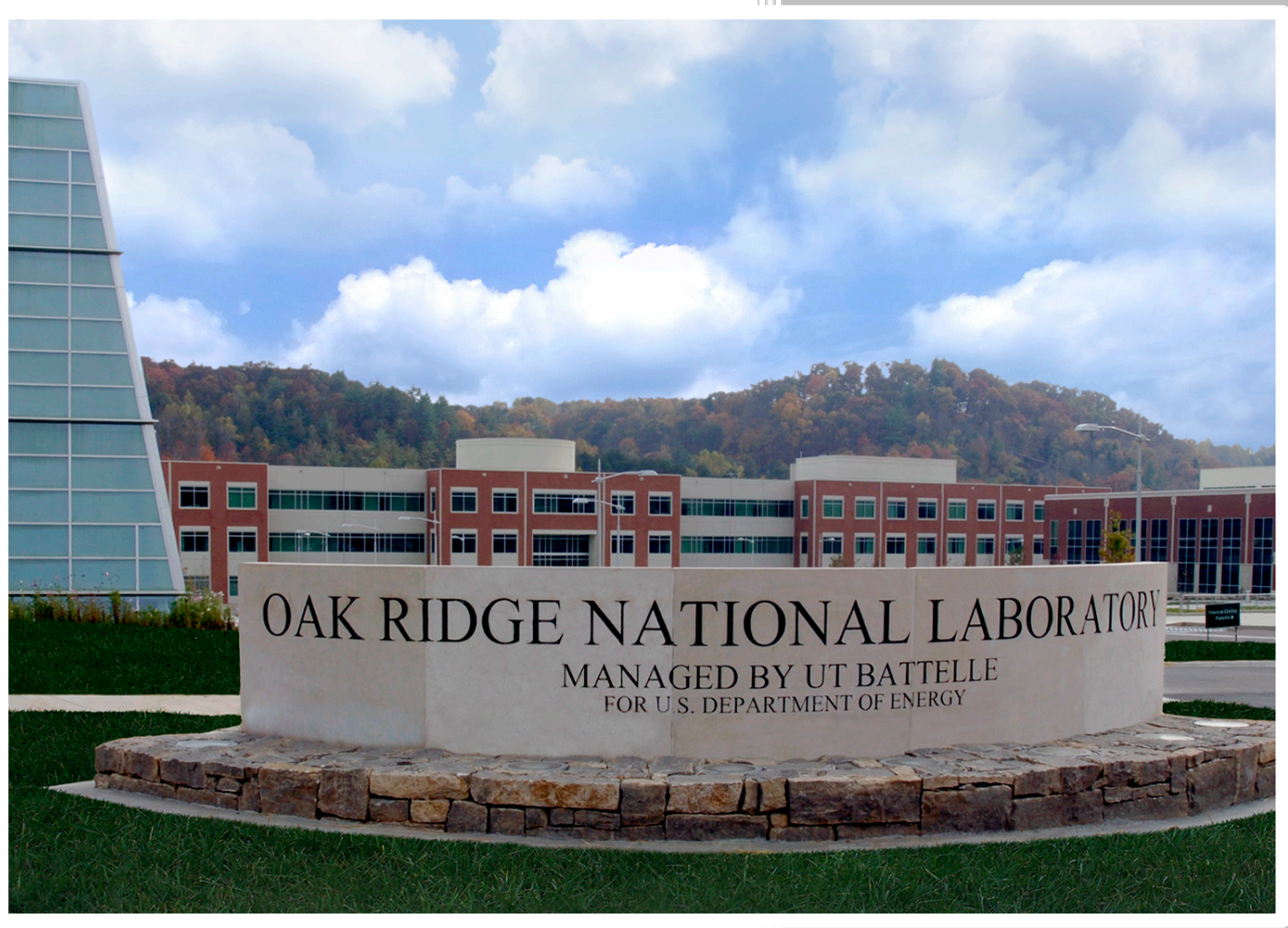

Approved for public release. Distribution is unlimited.
Kevin G. Field Maxim N. Gussev Yukinori Yamamoto Richard Howard Samuel Briggs

December 30, 2016 


\section{DOCUMENT AVAILABILITY}

Reports produced after January 1, 1996, are generally available free via US Department of Energy (DOE) SciTech Connect.

Website http://www.osti.gov/scitech/

Reports produced before January 1, 1996, may be purchased by members of the public from the following source:

National Technical Information Service

5285 Port Royal Road

Springfield, VA 22161

Telephone 703-605-6000 (1-800-553-6847)

TDD 703-487-4639

Fax 703-605-6900

E-mail info@ntis.gov

Website http://www.ntis.gov/help/ordermethods.aspx

Reports are available to DOE employees, DOE contractors, Energy Technology Data Exchange representatives, and International Nuclear Information System representatives from the following source:

Office of Scientific and Technical Information

PO Box 62

Oak Ridge, TN 37831

Telephone 865-576-8401

Fax 865-576-5728

E-mail reports@osti.gov

Website http://www.osti.gov/contact.html

This report was prepared as an account of work sponsored by an agency of the United States Government. Neither the United States Government nor any agency thereof, nor any of their employees, makes any warranty, express or implied, or assumes any legal liability or responsibility for the accuracy, completeness, or usefulness of any information, apparatus, product, or process disclosed, or represents that its use would not infringe privately owned rights. Reference herein to any specific commercial product, process, or service by trade name, trademark, manufacturer, or otherwise, does not necessarily constitute or imply its endorsement, recommendation, or favoring by the United States Government or any agency thereof. The views and opinions of authors expressed herein do not necessarily state or reflect those of the United States Government or any agency thereof. 
Nuclear Energy Enabling Technologies (NEET): Reactor Materials

\section{Second Annual Progress Report on Radiation Tolerance of Controlled Fusion Welds in High Temperature Oxidation Resistant FeCrAl Alloys}

Kevin G. Field, Maxim N. Gussev, Yukinori Yamamoto, Richard Howard, \& Samuel A. Briggs

Date Published: December $30^{\text {th }}, 2016$

Prepared by

OAK RIDGE NATIONAL LABORATORY

Oak Ridge, Tennessee 37831-6283

managed by

UT-BATTELLE, LLC

for the

US DEPARTMENT OF ENERGY

under contract DE-AC05-00OR22725 



\section{CONTENTS}

Page

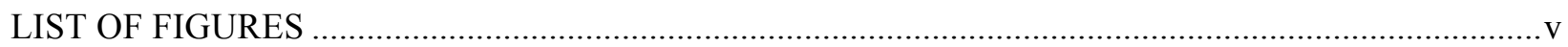

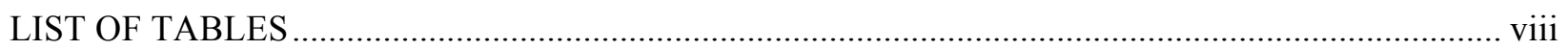

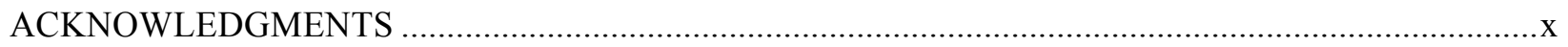

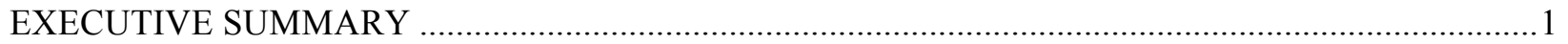

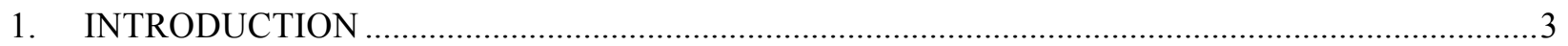

2. AS-RECEIVED AND WELDED MICROSTRUCTURE ......................................................

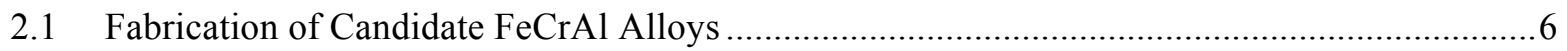

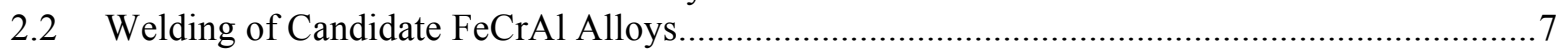

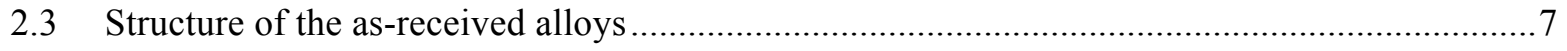

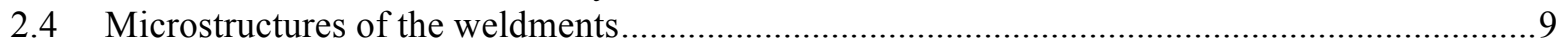

3. MECHANICAL PERFORMANCE OF NON-WELDED AND WELDED SPECIMENS

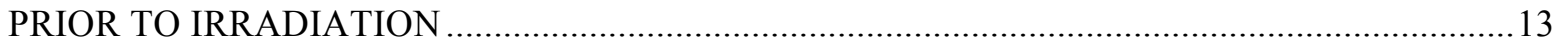

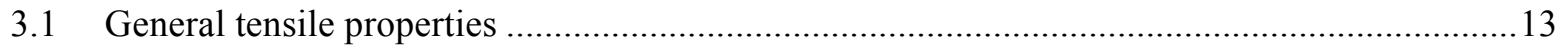

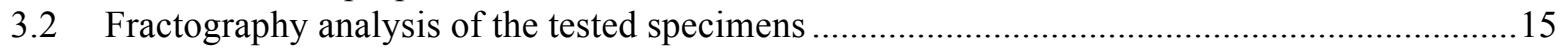

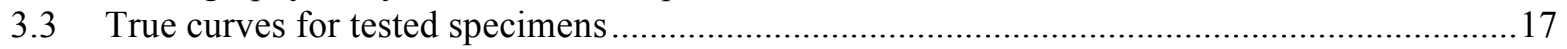

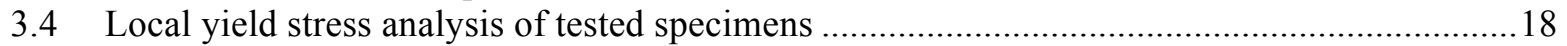

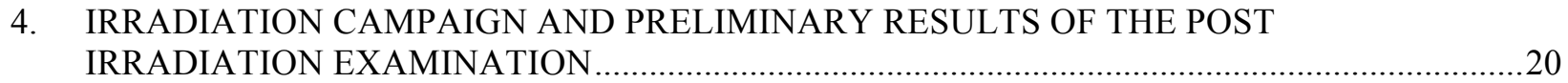

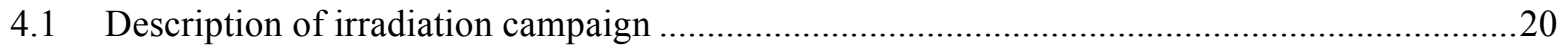

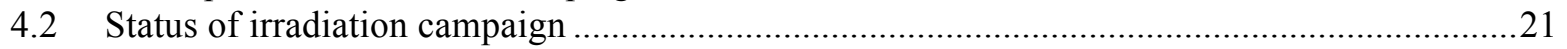

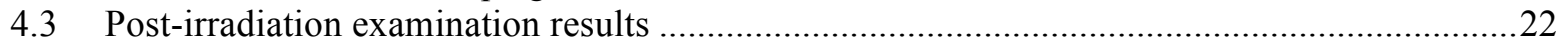

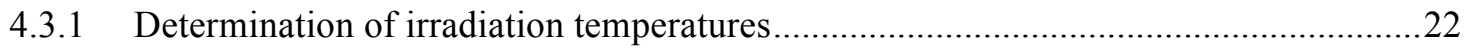

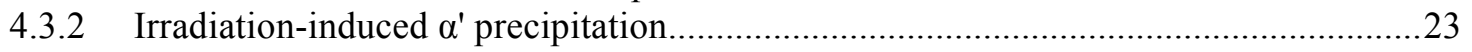

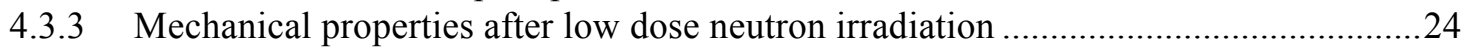

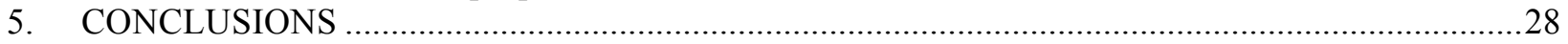

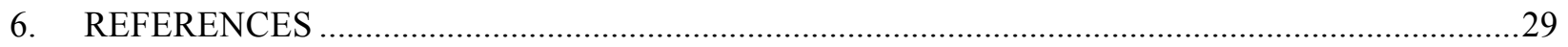





\section{LIST OF FIGURES}

Figure

Page

Figure 1. The alloying scheme showing two main branches: alloying with metallic elements (MEbranch - left) and TiC (TiC branch - right). All nominal values for composition are in wt.\%...

Figure 2. Composition design space for nuclear-grade $\mathrm{FeCrAl}$ alloys..................................................

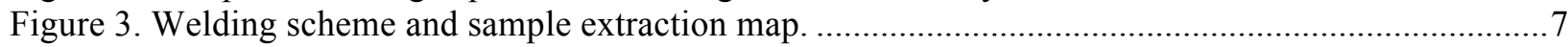

Figure 4. Typical EBSD results for the investigated materials: Inverse Pole Figure (IPF), IQ, and GROD maps.

Figure 5. The as-received texture of the $\mathrm{C} 35 \mathrm{M}$ alloy. Grains are strongly orientated close to the $\{101\}$ pole ([010] is a warm rolling direction). Similar texturing was found for all alloys, but not shown here for graphical simplicity.

Figure 6. Stitched EBSD IPF maps showing weldment structure for several alloys. Images for other alloys were omitted since the structure was very close to the $\mathrm{C} 35 \mathrm{M}$ alloy weldment.

Figure 7. Grain structure and grain boundary morphology in the weldment of C35M10TC alloy. Black dashed line approximately shows the weldment centerline.

Figure 8 . The transition between recrystallized and as-received structure (C35M alloy). Black arrows show the non-uniform movement of the recrystallization front; areas with small grains propagated into the parent material at a different rate (like streams) depending, most likely, on local texture variations.

Figure 9. TiC morphology in the C35M10TC alloy after alloy fabrication (left column), after welding (right top), and after fracture (fracture occurred in the weldment). Arrows point the TiC particles.

Figure 10: Simplified schematic of the tensile specimen geometries for weld and irradiation testing. Figure not to scale.

Figure 11. Representative tensile curves for the investigated material in the as-received conditions (AR, dotted blue curves) and after welding (Welded, solid red lines). Several curves are shown for the C35MN alloy to illustrate the brittle fracture cases. Black arrows point to sudden fracture events.

Figure 12. Representative fracture surface images for the investigated materials. Since ductile fracture was typical for all alloys in the as-received conditions, C35MN and C35M03TC were omitted from the figure.

Figure 13. Representative "True stress, MPa - true plastic strain" curves for the as-received materials (AR, dash blue lines) and for the weldments (solid red lines).

Figure 14. Yield stress distribution along the specimen gauge center line; zero corresponds to the weldment center which is also the gauge center; total gauge length is $5.036 \mathrm{~mm}$. Solid lines show the data for the weldments; dotted lines correspond to the yield stress of bulk parent material, Table 2

Figure 15: Internal components of the FCAT01 capsule during specimen loading. .................................20

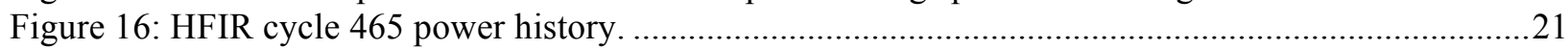

Figure 17. APT reconstruction of the $\mathrm{C} 35 \mathrm{M}$ alloy irradiated to 1.8 dpa near $364^{\circ} \mathrm{C}$. $\alpha^{\prime}$ precipitates are shown using a $\mathrm{Cr}$ concentration isosurface ( 25 at. $\%$ ). Black dots are $2 \%$ of the detected $\mathrm{Fe}$ atoms. Figure scale is in $\mathrm{nm}$.

Figure 18. Strain distribution along the gauge for the $\mathrm{C} 35 \mathrm{M}$ specimens irradiated to $364^{\circ} \mathrm{C}$ (top) and $559^{\circ} \mathrm{C}$ (bottom). The inserted diagram on the right demonstrates the tensile diagram and the location of the DIC frames. The main plot shows von Mises strain (vM); Green-Lagrange tensor was employed. The results may be expressed using any 
strain metric (engineering strain or true strain); however, Green-Lagrange strain definition is the most common one for DIC

Figure 19. Strain distribution (von Mises strain, vM, developed from Green-Lagrange tensor) along the gauge for the $\mathrm{C} 35 \mathrm{M}$ weldment irradiated at $559^{\circ} \mathrm{C}$ to $1.9 \mathrm{dpa}$. The inserted diagram at the right demonstrates the tensile curve and the location of the DIC frames (\#60, $\# 100$, etc.). 



\section{LIST OF TABLES}

\section{Table}

Page

Table 1: Candidate FeCrAl alloys processing routes and composition in weight percent. .........................6

Table 2. Mechanical properties of the modified alloys before and after welding .....................................14

Table 3: Thermal analysis conditions for a mixed SS-2E and SS-J2 tensile specimens' rabbit.................21

Table 4. Summary of FeCrAl capsule irradiation conditions. .............................................................22

Table 5: Results of dilatometric analysis of SiC thermometry bars contained within irradiated

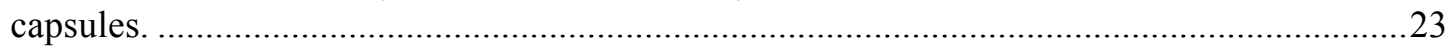

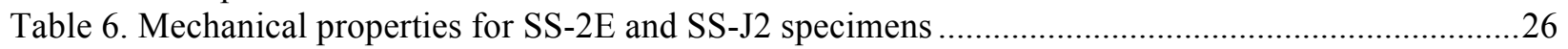





\section{ACKNOWLEDGMENTS}

This research was sponsored by the U.S. Department of Energy, Office of Nuclear Energy, for the Nuclear Energy Enabling Technologies (NEET) program for the Reactor Materials effort. This report was authored by UT-Battelle, LLC under Contract No. DE-AC05-00OR22725 with the U.S. Department of Energy. 


\section{EXECUTIVE SUMMARY}

The present report summarizes and discusses the current results and on-going activity towards developing a modern, nuclear grade $\mathrm{FeCrAl}$ alloy designed to have enhanced radiation tolerance and weldability under the Department of Energy (DOE) Nuclear Energy Enabling Technologies (NEET) program.

The alloys developed and characterized within year-one have undergone extensive experimental efforts including exhaustive as-received mechanical testing and evaluation in the non-welded and welded state as well as undergoing neutron irradiation within the High Flux Isotope Reactor (HFIR) at Oak Ridge National Laboratory (ORNL). On-going post-irradiation examination (PIE) has shown interesting results, including the role of welding on the radiation tolerance, and the value of the ultra-miniature SS-2E specimen developed in year-one is just now being fully realized and utilized. Work in regards to the hydrogen loading and embrittlement, that was on-going in year-one, has seen a significant decrease in experimental effort primarily due to limited variability in the alloys tested as well as the richness of data generated on the irradiated specimens warrants those specimens to see the most attention. Outlook into year-three, the final year of this program, looks promising as characterization of the lowest dose specimens will be completed. These efforts will lay the foundation for seeking follow-on funding to complete similar studies on the high dose specimens loaded in the HFIR in year-two thereby providing not only trends based on irradiation temperature and alloy composition but also dose from beginning-oflife to anticipated end-of-life applications.

Chapter 1 briefly summarizes the motivation and goals of the research and development program centered on developing a modern, nuclear grade $\mathrm{FeCrAl}$ alloy designed to have enhanced radiation tolerance and weldability. The current program has developed seven alloys to assess the role of composition and microstructure on these key issues. The program is centered around developing the FeCrAl alloy for accident tolerant fuel (ATF) cladding applications due to the FeCrAl alloy class having excellent environmental compatibility including aqueous corrosion, $\mathrm{Pb}$-alloy coolant compatibility, and oxidation resistance in high temperature steam [1-4]. Current developments have focused on enhancing their weldability and radiation tolerance as these have been identified as key issues (i.e. fabrication and in-core degradation) for the deployment of $\mathrm{FeCrAl}$ alloys as a commercial product within a nuclear power plant (NPP) [5].

Chapter 2 provides an overview of these alloy developments with a focus on the composition and microstructures of the alloys, drawing on the research completed in year-one of the program. Alloy developments were focused on modifying a base alloy, C35M, with a general composition of Fe-13Cr5Al-2Mo-0.2Si-0.05Y (in wt.\%). This base alloy resides within the expected composition space without known significant degradation issues such as weld-induced cracking and embrittling precipitation. The modified alloys included two main alloy schemes, the first being altering the metal content while the other included the inclusion of secondary phases such as TiC. These alloys were assessed using optical microscopy and advanced electron microscopy based techniques.

Chapter 3 outlines the results of mechanical tests completed to date using both SS-J and SS-2E type specimens in the welded and non-welded states. Since mechanical performance of the weldments is a key concern in many industrial applications, the pre-irradiation results are presented as a separate chapter. The non-irradiated specimens were characterized in detail using advanced tensile tests with digital image correlation (DIC), scanning electron microscopy-electron backscattered diffraction (SEM-EBSD) analysis, and fractography. All developed alloys demonstrated yield stress in the weldment over $500 \mathrm{MPa}$; no welding-induced cracking was observed. It was shown that the increase in the Al-content over 5\% was detrimental from a mechanical performance point of view leading to brittle fracture and decreased ductility in the weldment. At the same time, $\mathrm{Nb}$ and $\mathrm{TiC}$ additions were beneficial for preventing grain 
growth and reducing local softening (yield stress reduction) in the heat-affected zone. $1 \%$ TiC addition also effectively refined grain size in the weldment.

Chapter 4 provides the detailed insight into post-irradiation examination (PIE) and current irradiation campaign at the High Flux Isotope Reactor (HFIR) including a summary of the specimen and capsule design and the current timeline of the irradiation experiment. Chapter 4 has a special focus on the ongoing PIE with the neutron irradiated samples. The observed irradiation responses were consistent with the literature on other high chromium ferritic alloys. Irradiations at $195^{\circ} \mathrm{C}$ and $364^{\circ} \mathrm{C}$ resulted in significant radiation-induced hardening and embrittlement with the severity scaling inversely with the irradiation temperature. Irradiations at $559^{\circ} \mathrm{C}$ lead to radiation-induced softening in the base metal and little to no change in the mechanical properties of the welded specimens. Use of DIC shows that the base material deformed uniformly under straining until necking while local maxima in the strain distribution along the neck can be observed in weldments. Good agreement between the SS-2E type and SS-J type specimens suggests the valid use of the SS-2E specimen geometry for screening mechanical properties while extracting further information using advanced experimental techniques.

The results and discussion presented in the following report provides a brief overview of the program currently in place focused on optimizing both the microstructure and chemistry of the FeCrAl alloy class to obtain the necessary properties and performance for nuclear power applications including weldability, thermal stability, and radiation tolerance. 


\section{INTRODUCTION}

Current and potential power plant designs call for materials that can withstand harsh and extreme environments: elevated temperature, high mechanical stresses, acute and chronic corrosive media attack, to name a few. In the case of nuclear power plants (NPPs), radiation tolerance and ability to survive under normal and off-normal conditions, like Lost-of-Coolant Accidents (LOCA) [1] are also important material performance metrics. One class of materials showing initial promise as new, robust materials for nuclear power production is the metallic, iron-based iron-chromium-aluminum ( $\mathrm{FeCrAl})$ alloy class. These alloys have shown excellent environmental compatibility, including resistance to aqueous corrosion, $\mathrm{Pb}$-alloy coolant compatibility, and oxidation resistance in high-temperature steam $[1,4,6,7]$. It is worthwhile to note their low radiation-induced swelling [8] and tolerance to the LOCA conditions [1,4,9] indicates their use as an accident tolerant fuel (ATF) cladding. This complex network of beneficial properties for NPP use makes the $\mathrm{FeCrAl}$ alloy class promising for further development.

Generally, $\mathrm{FeCrAl}$ alloys with less than $\sim 12 \mathrm{wt} . \% \mathrm{Al}$ can be processed using several different techniques, including traditional wrought processing routes and more modern powder metallurgy [10]. Additionally, wrought material has been shown to have the capability to form thin-walled tubes suitable for cladding material in a NPP [11,12]. Good weldability is essential in a fuel-cladding application; however, several reports have indicated that $\mathrm{FeCrAl}$ alloys may be susceptible to cracking during welding. For example, Regina et al. [13] and Dupont et al. [14] have shown that FeCrAl weld overlays have a higher susceptibility to welding-induced cracking when high-Cr and/or high-Al variants are used. Such a lack of processability is a technological limiting factor for $\mathrm{FeCrAl}$ deployment in NPPs.

Typically, advanced modern materials have highly tailored microstructures and microchemistry that enhance their performance. The high heat input from fusion-based welding leads to localized melting of the material and inevitably the destruction or, at a minimum, degradation of the tailored microstructure and microchemistry at and near the weld. Even in regions outside the fusion zone, localized heating can be at or above critical temperatures - for example, the critical temperature for recrystallization - leading to additional changes in microstructure. These regions are typically referred to as heat-affected-zones (HAZs) and often experience increased stresses and strains from shrinking during weldment cooling.

Thus, regardless of the performance and promises of advanced $\mathrm{FeCrAl}$ alloys, their weldability and weldment performance should be examined in detail. The cracking susceptibility during welding and the resulting microstructure and mechanical properties after welding should be determined. To address this need, a research and development program centralized on the use of candidate $\mathrm{FeCrAl}$ alloys to assess the fusion-based weldability and radiation tolerance of these alloys has been initiated. This program was initiated in the United States 2015 fiscal calendar year under the Department of Energy (DOE) Nuclear Energy Enabling Technologies (NEET) program.

Previous activities within this program [15-19] included the development of an alloying scheme to mitigate welding induced cracking while making radiation tolerant base alloys. These alloys were developed on prior $\mathrm{FeCrAl}$ alloy development efforts, including model alloy welding developments which demonstrated good weldability but had relatively low weldment strength ( $\sim 360 \mathrm{MPa})$ [20]. Nonwelded versions of these model alloys have also been neutron irradiated in the HFIR and showed that higher $\mathrm{Cr}(>12 \mathrm{wt} . \%)$ variants suffered from significant hardening from the formation of the $\alpha^{\prime}$-phase during aging or irradiation [21-23]. To overcome these issues, two different alloy refinement strategies on a base-13 wt.\% $\mathrm{Cr} \mathrm{FeCrAl}$ variant were offered and used: (1) varying the amount of the metallic alloying elements ( $\mathrm{Al}$ and $\mathrm{Nb}$, or ME-branch of alloys), and (2) adding precipitate dispersions (TiC-branch) into the matrix to reduce weld cracking susceptibility and promote better microstructural and microchemistry changes after welding. An alloy designated as C35M (Fe-13Cr-5Al, in wt.\%) was used as the base- 
reference material. The remaining alloys exist as distinguished variants from the C35M grade. The alloying strategies are summarized in Figure 1.

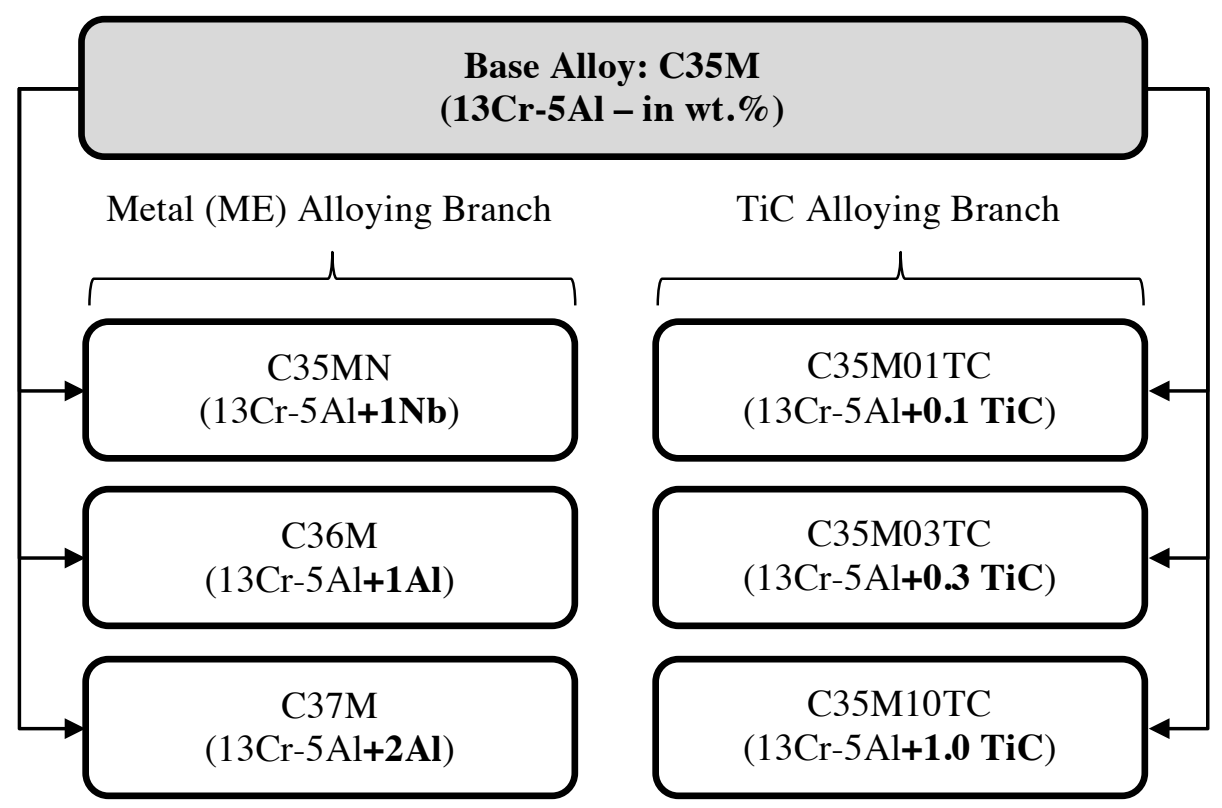

Figure 1. The alloying scheme showing two main branches: alloying with metallic elements (MEbranch - left) and $\mathrm{TiC}$ (TiC branch - right). All nominal values for composition are in wt.\%.

The ME-branch in Figure 1 is designed to explore the effects of $\mathrm{Al}$ and $\mathrm{Nb}$ additions on weld-induced cracking. For example, Regina et al. [13] established a composition-based cracking boundary for FeCrAl alloys. Their data, reproduced in modified form in Figure 2, show that the base alloy C35M exists close to, if not on, the cracking boundary. It happens by the possible circumstance that $\mathrm{C} 35 \mathrm{M}$ also sits nearly on the phase boundary for the formation of the Cr-rich $\alpha^{\prime}$ phase at moderate to low temperatures $\left(\leq 475^{\circ} \mathrm{C}\right)$, as proposed by Kobayashi and Takasugi [21]. The formation of the Cr-rich $\alpha^{\prime}$ phase has been linked to significant hardening and embrittlement in aged and/or irradiated $\mathrm{FeCr}$ and $\mathrm{FeCrAl}$ alloys [22-28].

The $\alpha-\alpha$ ' phase boundary is also overlaid onto the data from Regina et al. to show the overlapping regions where the Cr-rich $\alpha^{\prime}$ phase is postulated to form under long-term thermal aging and where cracked weldments are found. Note that the phase boundary proposed by Kobayashi and Takasugi was based on a change in the hardness of diffusion couple-like experiments after thermal aging at $475^{\circ} \mathrm{C}$. It is possible, even probable, that the phase boundary is not completely accurate and that the $\alpha$ - $\alpha^{\prime}$ regime is larger in Figure 1. Hence, the C35M alloy could exist in the $\alpha-\alpha^{\prime}$ phase regime, as could the high-Al variants shown in Figure 2. Hence, the inclusion of the C36M and C37M alloys in the test matrix will explore the possible delicate balance between the phase boundary and the weld-induced cracking boundary.

It is worthwhile to underline there are a number of additional limitations in regards to FeCrAl alloy design for NPP use. For example, a boundary exists for Pb-corrosion resistance [29] as well a boundary for the ability for a FeCrAl alloy to be worked in both warm or cold condition (such as cold-shaping in the tube drawing process) [10]. These boundaries are also shown schematically in Figure 2. Thus, decreasing Cr-amount will shift the material in the good weldability area with better workability, but strongly reduces the oxidation and corrosion performance. Al-amount reducing will lead to the loss of high-temperature oxidation resistance. The result is only a limited modification can be made by varying either the $\mathrm{Cr}$ or $\mathrm{Al}$ amount as shown in Figure 2. 


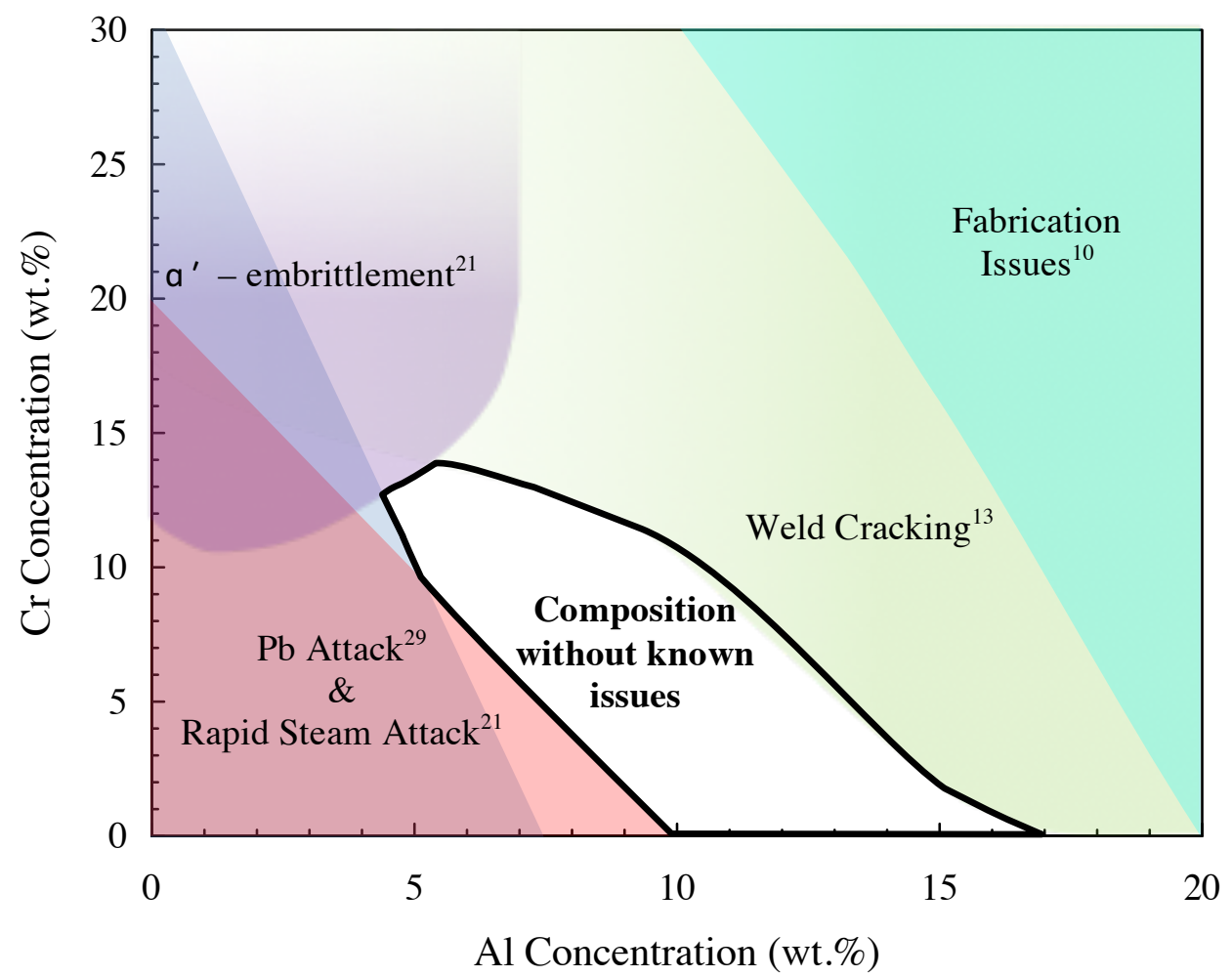

Figure 2. Composition design space for nuclear-grade FeCrAl alloys. Regimes determined from Refs. $[9,10,13,21,29]$.

As only small modifications can be made in regards to the $\mathrm{Cr}$ or $\mathrm{Al}$ composition for properties optimization, minor alloying additions and precipitation additions are the next logical method for increasing the weldability of the nuclear-grade FeCrAl alloy class. Hence, within the ME-branch minor alloying additions of niobium, C35MN, was studied. As expected, excess niobium will form Laves phase precipitates during typical processing routes. It was speculated that welding-induced embrittlement is caused, at least partly, by hydrogen $[13,14]$, and hydrogen trapping by precipitate phases may reduce or eliminate cracking during welding.

The $\mathrm{C} 35 \mathrm{MN}$ alloy refinement is like the TiC-alloying scheme except that the addition was intrinsic and did not require special processing routes. In both cases $(+\mathrm{Nb}$ and $+\mathrm{TiC})$, the precipitates, either Laves phase or $\mathrm{TiC}$, were added to the matrix microstructure to introduce benign hydrogen trapping sites. These sites (small carbide or Laves phase particles) have been shown initially to reduce welding-induced cracking [14]. They also could act as pinning sites in solidification and recrystallization during welding and hence have an inherent ability to help maintain the base microstructure or at least retard significant grain growth in the weldment. 


\section{AS-RECEIVED AND WELDED MICROSTRUCTURE}

\subsection{Fabrication of Candidate FeCrAl Alloys}

Fabrication and general microstructure of the as-received and welded alloys have been reported previously [17] and duplicated here for completeness. The alloys shown in Figure 1 were generated using two different processing routes: vacuum induction melting (VIM) and arc melting with drop-casting. The resulting compositions for each alloy, as determined by a commercial outside vendor, are provided in Table 1. Fabrication of the C35M, C36M, C37M, and C35MN alloys was completed using VIM by a commercial vendor. The VIM ingots were homogenized at $1200^{\circ} \mathrm{C}$ in an argon gas atmosphere for $4 \mathrm{~h}$, followed by air cooling for a few minutes, followed by water quenching. Air cooling was completed to avoid a potential crack formation due to thermal shock from the water quenching procedure. The ingots were sectioned into small pieces, hot forged at $800^{\circ} \mathrm{C}$ with total $50 \%$ thickness reduction to make plateshaped samples. The plates were hot-rolled at $800^{\circ} \mathrm{C}$ with an additional $40 \%$ reduction and then annealed at $800^{\circ} \mathrm{C}$ in laboratory air for $1 \mathrm{~h}$. The resulting total thickness reduction was $70 \%$ after this step. The plates were then warm-rolled at $300^{\circ} \mathrm{C}$ with an $80-90 \%$ total thickness reduction from the hot-rolled plates and then annealed at $650^{\circ} \mathrm{C}$ for $1 \mathrm{~h}$ in air.

Fabrication of the C35M01TC, C35M03TC, and C35M10TC alloys was completed using arc melting with drop casing. Commercial TiC powder with nominal 0.1, 0.3, and $1.0 \mathrm{wt} . \%$ were mixed with C35M (in Table 1, used as a master alloy) by arc-melting. The TiC powder was placed on the bottom of the water-cooled copper hearth in the arc-melt furnace, and then the master alloy was set on the powder. The first arc-melt was conducted on melting only the master alloy to cover all powder by the molten master alloy. The first melt typically resulted in only embedding the non-melted $\mathrm{TiC}$ powder at the bottom of the button ingot because of the surface tension of the TiC powder. The ingot was then flipped to make the embedded TiC powder lay on the top of the ingot, and then the second arc-melt was conducted to melt the TiC powder first. The melted $\mathrm{TiC}$ tended not to be miscible with the molten master alloy but flow on the top of the liquid during arc-melting. The flipping and arc-melting were repeated several times until the melted $\mathrm{TiC}$ was completely miscible in the liquid. Once the mixing was completed, the ingot was dropcast in the mold. Finished ingots were homogenized at $1200^{\circ} \mathrm{C}$ in an argon gas for $1 \mathrm{~h}$, followed by the same air-cooling and water-quenching procedure as the VIM ingots. The ingots were hot-forged and hotrolled at $800^{\circ} \mathrm{C}$ with more than $80 \%$ total thickness reduction. The rolled plates were further warm-rolled at $300^{\circ} \mathrm{C}$ with $90 \%$ total thickness reduction, and then annealed at $650{ }^{\circ} \mathrm{C}$ for $1 \mathrm{~h}$ in air.

Table 1: Candidate FeCrAl alloys processing routes and composition in weight percent.

\begin{tabular}{ccccccccccccccc}
\hline Alloy & Fe & Cr & Al & Y & Mo & Si & Nb & C & S & O & N & P & Ti \\
\hline \hline C35M $^{1}$ & 79.43 & 13.06 & 5.31 & 0.053 & 2 & 0.13 & $<0.01$ & 0.001 & $<0.0003$ & 0.0012 & 0.0003 & 0.007 & $<0.01$ \\
C36M $^{1}$ & 78.8 & 12.98 & 6 & 0.04 & 1.98 & 0.18 & $<0.01$ & 0.003 & $<0.0003$ & 0.0016 & 0.0002 & $<0.002$ & 0.01 \\
C37M $^{1}$ & 77.49 & 13.01 & 7.22 & 0.081 & 1.99 & 0.19 & $<0.01$ & 0.001 & $<0.0003$ & 0.0026 & 0.0002 & 0.004 & $<0.01$ \\
C35MN $^{1}$ & 78.7 & 13 & 5.11 & 0.044 & 1.99 & 0.18 & 0.96 & 0.005 & 0.0003 & 0.0014 & 0.0002 & $<0.002$ & - \\
C35M01TC $^{2}$ & 79.51 & 13 & 5.2 & 0.04 & 1.98 & 0.15 & $<0.01$ & 0.024 & $<0.0003$ & 0.0009 & 0.0004 & 0.002 & 0.08 \\
C35M03TC $^{2}$ & 79.34 & 13.03 & 5.17 & 0.04 & 1.97 & 0.15 & $<0.01$ & 0.058 & $<0.0003$ & 0.0009 & 0.0003 & 0.003 & 0.22 \\
C35M10TC $^{2}$ & 78.82 & 12.95 & 5.14 & 0.01 & 1.96 & 0.2 & $<0.01$ & 0.18 & $<0.0003$ & 0.0012 & 0.0007 & $<0.002$ & 0.71 \\
\hline
\end{tabular}

All other elements $(\mathrm{Zr}, \mathrm{B}, \mathrm{Hf}, \mathrm{V}, \mathrm{W}, \mathrm{Ce}, \mathrm{Co}, \mathrm{Cu}, \mathrm{La}, \mathrm{Mn}, \mathrm{Ni})$ measured to be at or below $<0.01$

${ }^{1}$ VIM ingot, ${ }^{2}$ Arc-melt and drop cast ingot 


\subsection{Welding of Candidate FeCrAl Alloys}

Autogenous, bead-on-plate welding was performed to simulate welding procedures used for fuel-cladding in a commercially-based fabrication route. Full penetration welds were produced using a pulsed laserwelding machine with operating parameters of $7 \mathrm{~ms}$ pulse length, 7 pulses/s and a $2.12 \mathrm{~mm} / \mathrm{s}$ welding speed. Lamp energy was maintained near 100 Watts for the duration of the welding. An argon cover gas was used during welding to reduce oxidation and contamination of the weldments. Produced weldments were used for both microstructural characterization and mechanical evaluation. All mechanical testing specimens were extracted using electric discharge machining (EDM) in the cross-weld orientation (rolling direction is along the load direction) with the fusion zone centered within the gauge region of the dogbone shaped tensile specimens, Figure 3. Surfaces were mechanically polished to final thickness using standard metallographic techniques with surface roughness of $1.6 \mu \mathrm{m}$ or better.

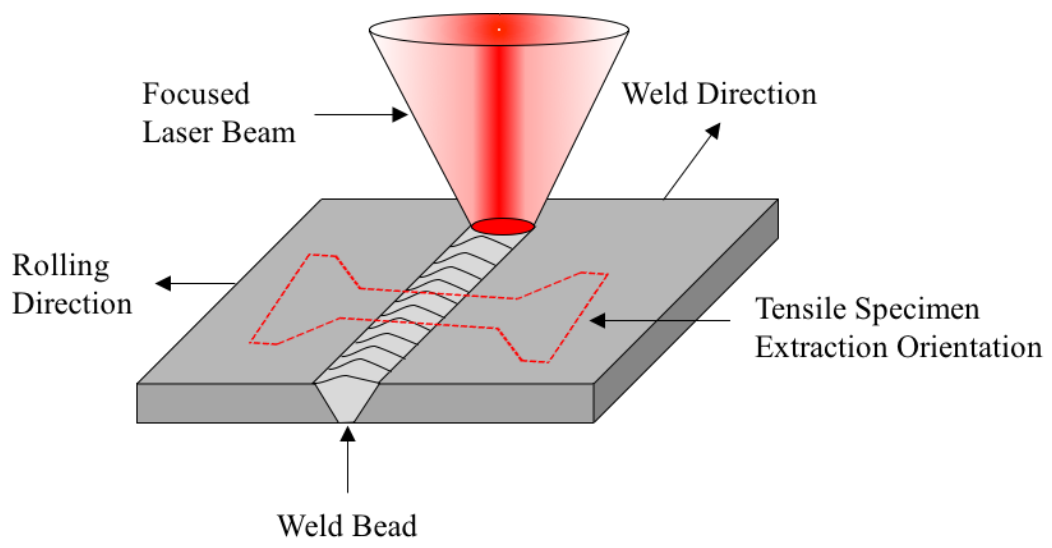

Figure 3. Welding scheme and sample extraction map.

The weldments were analyzed visually using optical microscopy for porosity, visible non-metallic inclusions, and cracks. For all investigated alloys, no voids, rough inclusions, cracks, or other welding defects were observed with magnification up to 100-200×. Several weldment cross-sections per alloy were prepared for the SEM-EBSD analysis (see below); no cracks or pronounced porosity were observed. All analyzed welds were determined to be crack free using the described methods.

\subsection{Structure of the as-received alloys}

All alloys showed a fully-ferritic microstructure under optical microscopy, but the average nominal grain size and secondary phase dispersions varied depended on the investigated alloy. Figure 4 shows typical microstructures of the investigated alloys using SEM-EBSD - C36M, C35MN and C35M03TC are omitted from Figure 4 as their microstructures are similar to the observed microstructures of the other alloys within their respective alloying branch. SEM-EBSD can provide more robust measurements on the grain size, texture (orientation), and grain shape compared to the traditional optical microscopy. All samples for investigation were carefully polished using standard metallography practices to produce a defect free, mirror-like surface. Colloidal silica polishing was used as the last preparation step. 

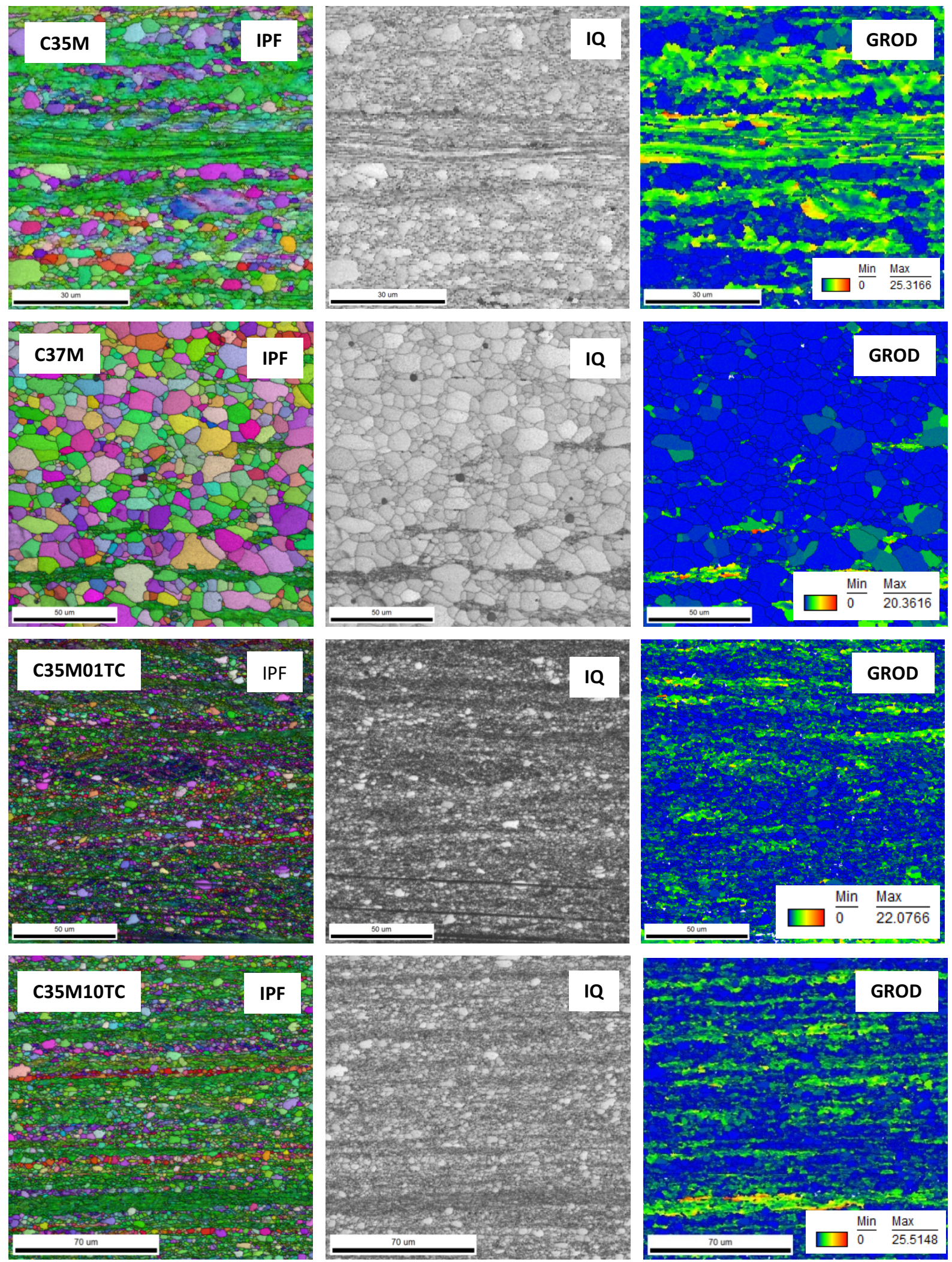

Figure 4. Typical EBSD results for the investigated materials: Inverse Pole Figure (IPF), IQ, and GROD maps. 
All alloys showed microstructure consistent with warm-rolled material conditions, with a mix of deformed (non-recrystallized) and recrystallized grains. The deformed grains were elongated along the rolling direction, and had darker color in the Image Quality (IQ) maps and higher Grain Reference Orientation Deviation (GROD) values. Grains, which appeared to be recrystallized, had a generally larger size and round or rounded shapes; they also had brighter color in the IQ map and lower GROD values due to the reduced defect density. The recrystallized grains formed specific chains, also elongated in the rolling direction. An alternating mix of recrystallized and non-recrystallized grains resulted in a pronounced band-like microstructure. All alloys exhibited strong texturing near the [101] corner of the unit triangle (with respect to the warm rolling direction which was also the tensile direction). Typical IPF for the C35M alloy is given in Figure 5.

Instead of nominally identical processing routes, recrystallization degree varied for the investigated materials. The C35M (Figure 4) and C35MN (not shown) alloys experienced moderate recrystallization, whereas $\mathrm{C} 37 \mathrm{M}$ demonstrated almost fully $(>90 \%)$ recrystallized structure with well-shaped grains and just a few remaining non-recrystallized spots, Figure 4. Recrystallization was less pronounced in the C35M01TC, C35M03TC, and C35M10TC alloys with TiC-addition. The size of the recrystallized grains was significantly smaller in these alloys compared to the C35M and C37M, indicating the role of TiC addition on grain refinement.

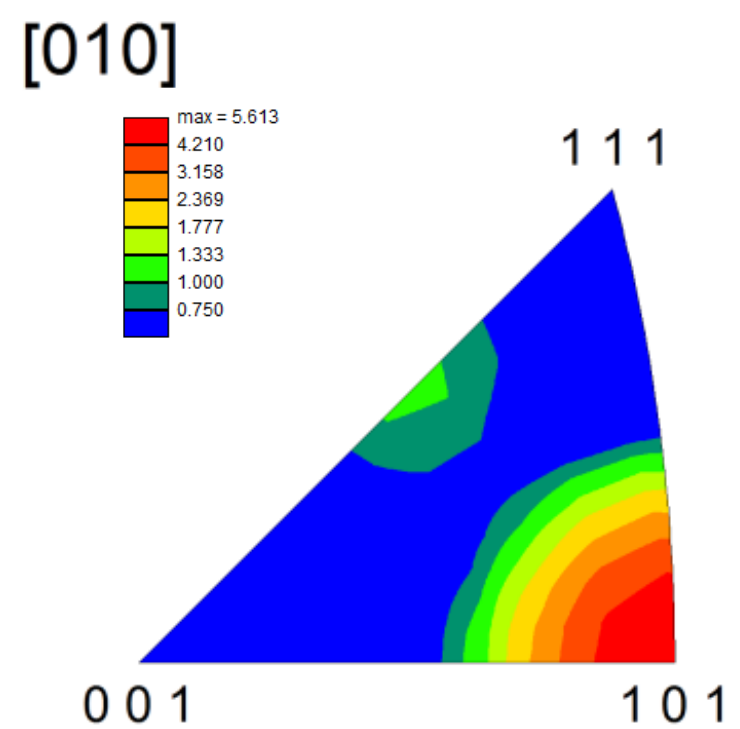

Figure 5. The as-received texture of the C35M alloy. Grains are strongly orientated close to the $\{101\}$ pole ([010] is a warm rolling direction). Similar texturing was found for all alloys, but not shown here for graphical simplicity.

\subsection{Microstructures of the weldments}

Due to the relatively large size of the primary feature (the fusion zone), several EBSD maps were generated and then stitched together to provide a full field-of-view of the weldment. Figure 6 shows the stitched image of the investigated alloy weldments. For most alloys (C35M, C37M, C35M01TC, and C35M03TC), welding led to the formation of relatively large grains of irregular shapes near the weldment centerline. This feature was complemented by elongated or columnar grains which appeared roughly 200$300 \mu \mathrm{m}$ away from the centerline. The width of the columnar-grain area was on the order of $300 \mu \mathrm{m}$.

Nearly $\sim 600 \mu \mathrm{m}$ away from the centerline, a distinct area of course-grained, yet round-shaped grains, was observed. It is believed this region is the HAZ, where melting did not occur, but the specimen temperature 
during welding in the HAZ exceeded the recrystallization temperature for the materials. Materials with $\mathrm{Nb}$ - and $\mathrm{TiC}$-additions demonstrated smaller grain growth.

Interestingly, the C35M10TC had a distinctly different microstructure in the fusion zone compared to the other observed alloys. The grain size of the fusion zone was significantly reduced, on the order of 3-5 times smaller. The columnar grain area was also smaller, and appeared more elongated. The grains within the fusion zone were also different, with more torturous boundaries dominating the weldment, Figure 7. Based on the observed microstructures in Figure 6, the 1\%-addition of $\mathrm{TiC}$ appeared to increase the fraction of grain boundaries pinned during the melt and solidification process. The pinning of grain boundaries limited grain growth resulting in a reduced grain size in the fusion zone of this alloy.
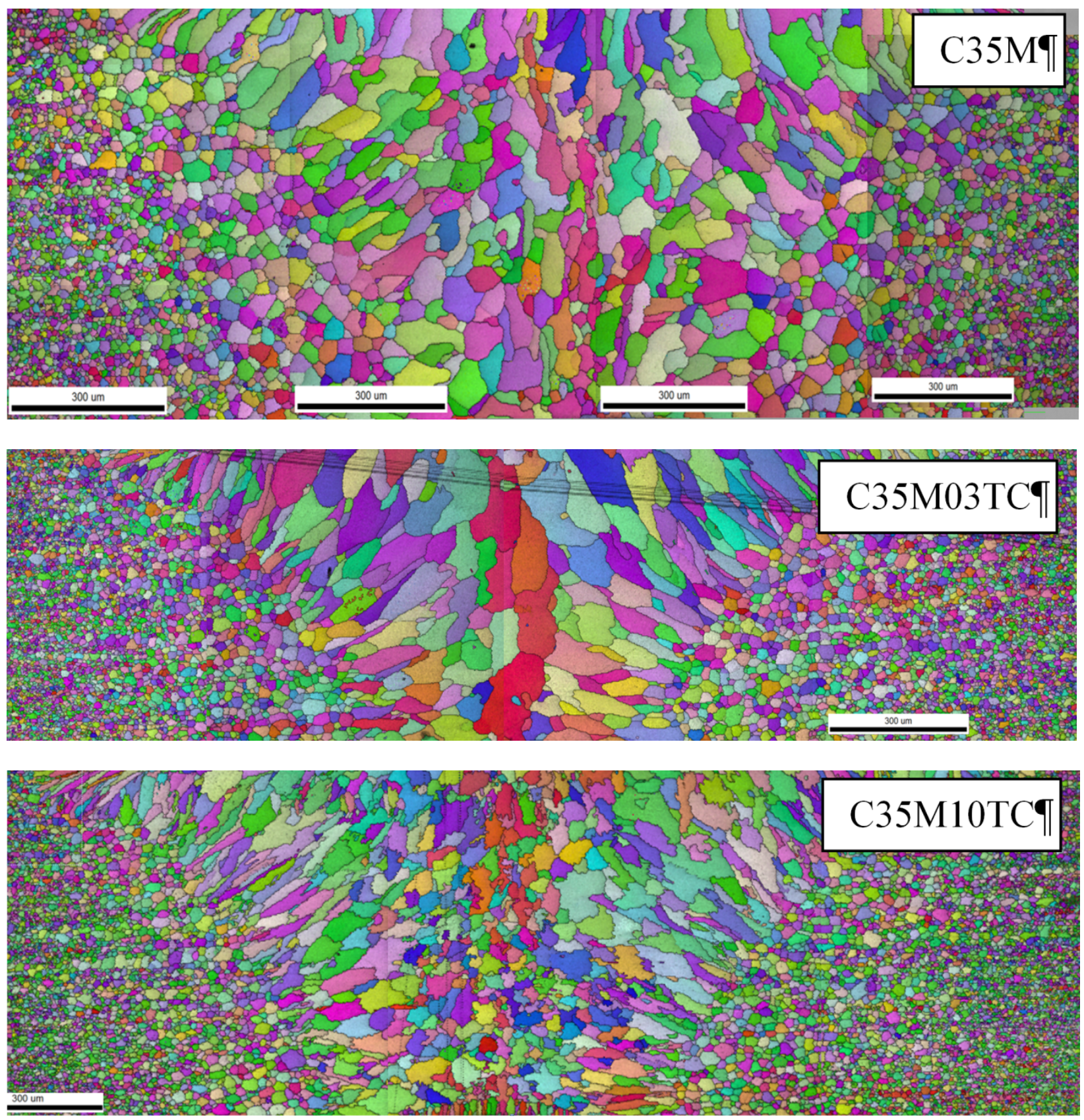

Figure 6. Stitched EBSD IPF maps showing weldment structure for several alloys. Images for other alloys were omitted since the structure was very close to the $\mathrm{C35M}$ alloy weldment. 
The grain boundary pinning appeared in the fusion zone only, where base metal melting occurred, but in areas where the temperature did not exceed the melting point, such as in the elongated grain region and coarse-grained region, the addition of $\mathrm{TiC}$ did not have a significant effect on the grain morphology.

Another interesting feature was related to the transition between grain growth area and parent material, Figure 8. After analyzing IQ and IPF maps, it appears that recrystallization front moved non-uniformly. Most likely, grain growth occurred depending on the local grain orientation and, in the result, the areas of recrystallized grains penetrated in the parent material like streams or lines. Small spots of nonrecrystallized material, having darker color in the IQ map, survived after the general recrystallization front passed this point.

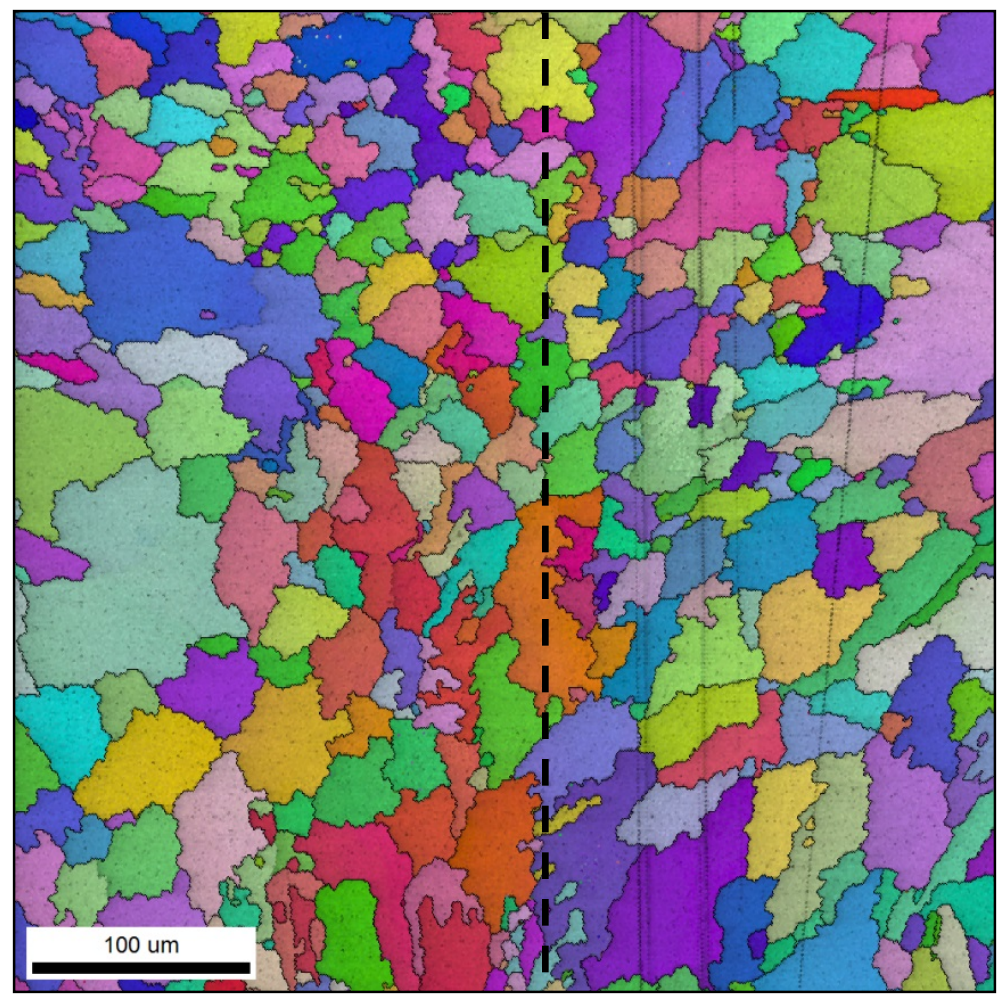

Figure 7. Grain structure and grain boundary morphology in the weldment of C35M10TC alloy. Black dashed line approximately shows the weldment centerline.

Since the TiC-addition employed in the current work is not a common addition, it is worth providing more detailed information. Figure 9 shows the TiC particle morphology under different conditions. In the as-received bulk material, prior to welding (Figure 9, left column), the particles had size $\sim 1-4 \mu \mathrm{m}$ and were more or less uniformly distributed in the volume. Many particles contained internal cracks introduced, most likely, during rolling. The TiC particle morphology changed significantly after welding. Particles became smaller, much less than $1 \mu \mathrm{m}$ and tended to form "lines" or "stringers". The direction of such "lines" varied across the weldment and between grains. After the tensile test, elongated voids were observed at the $\mathrm{TiC}$ particle locations inside the weldment. Most likely, the TiC particles experienced partial melting under welding and during solidification finer TiC particles precipitated again sometimes pinning the grain boundaries. 


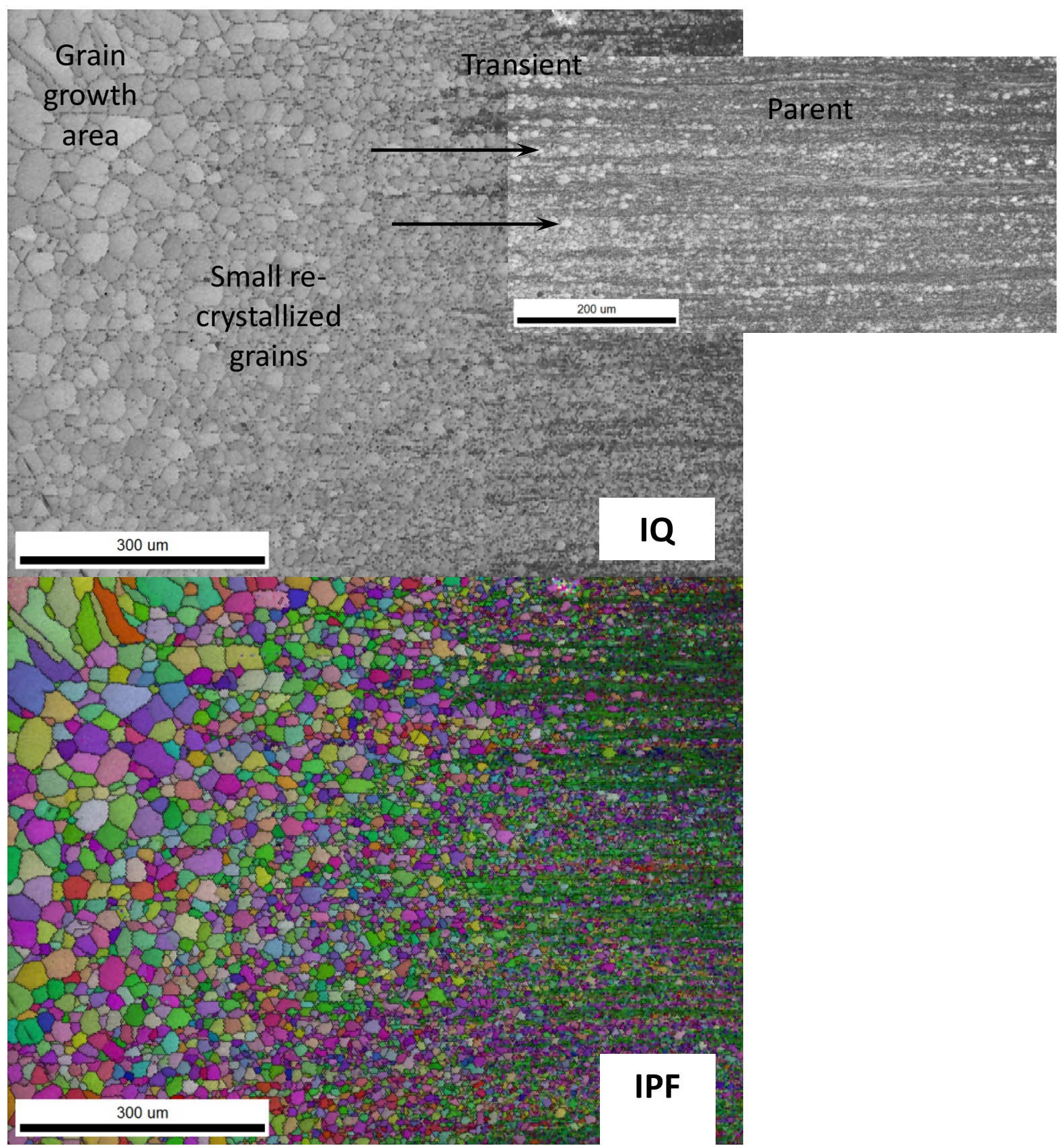

Figure 8. The transition between recrystallized and as-received structure (C35M alloy). Black arrows show the non-uniform movement of the recrystallization front; areas with small grains propagated into the parent material at a different rate (like streams) depending, most likely, on local texture variations. 

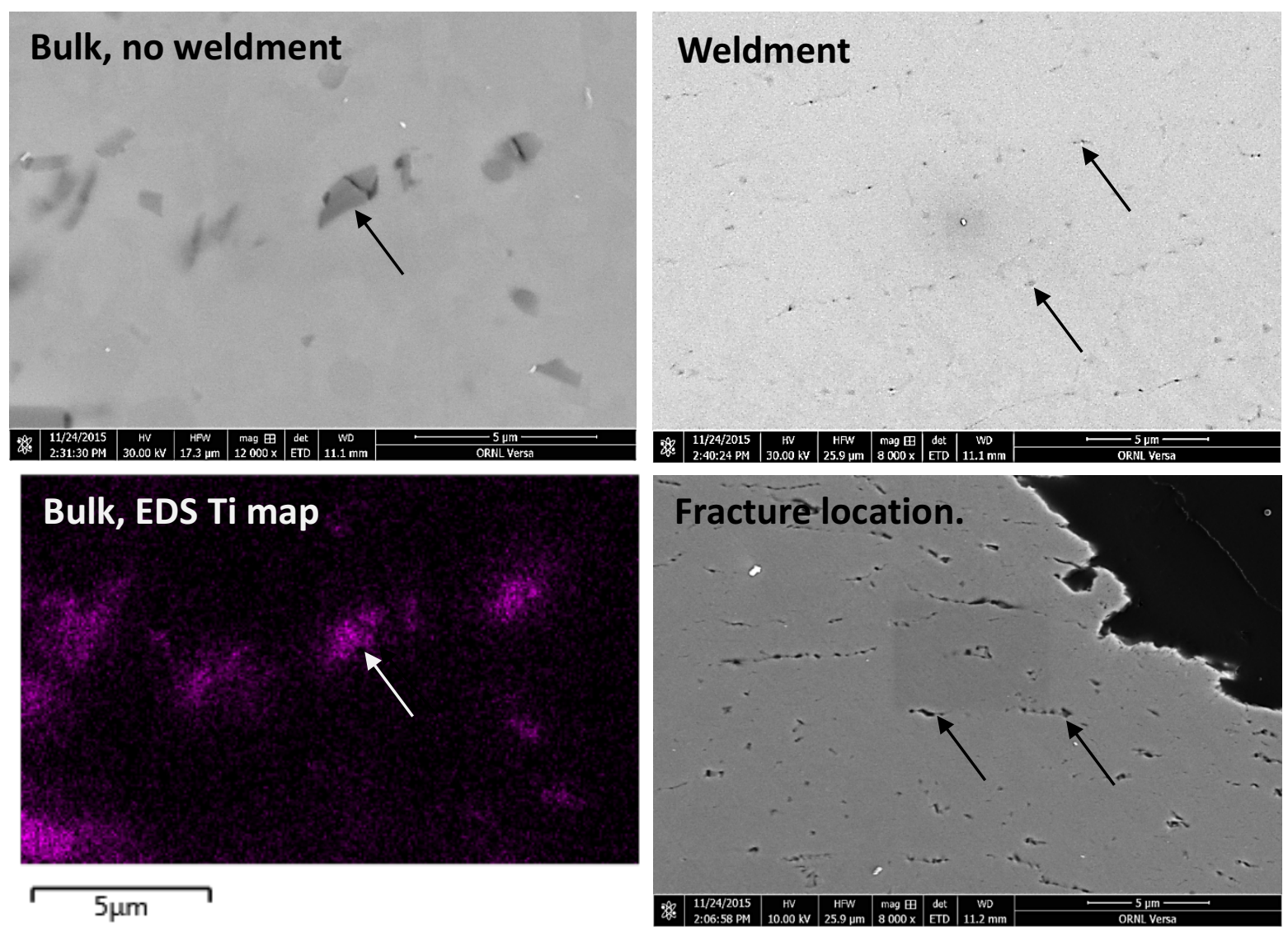

Figure 9. TiC morphology in the C35M10TC alloy after alloy fabrication (left column), after welding (right top), and after fracture (fracture occurred in the weldment). Arrows point the TiC particles.

\section{MECHANICAL PERFORMANCE OF NON-WELDED AND WELDED SPECIMENS PRIOR TO IRRADIATION}

\subsection{General tensile properties}

The SS-J2 tensile specimen geometry was used to establish the baseline mechanical performance data of the candidate FeCrAl alloys. The SS-J2 specimen geometry is shown in Figure 10. The detailed description of the mechanical test conditions (grips geometry, tensile frame, DIC setup) are given in our previous reports $[12,13]$. The testing was conducted at room temperature. The nominal strain rate was $10^{-}$ ${ }^{3} \mathrm{~s}^{-1}$; due to strain localization in the weldment area, local strain values might vary. The C36M alloy was excluded from extensive mechanical testing as it closely replicated the results of C35M and hence redundant in the test matrix. 


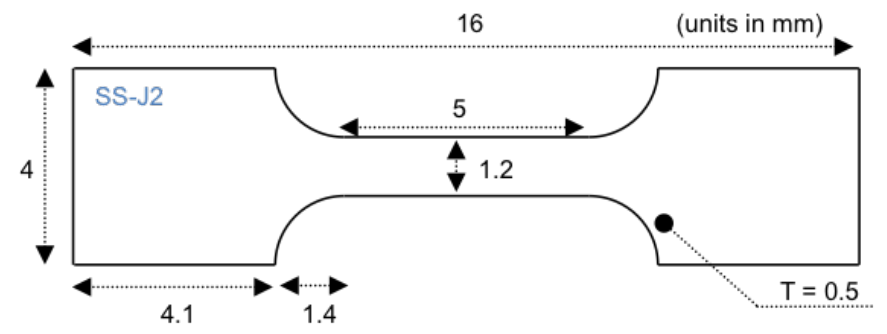

Figure 10: Simplified schematic of the tensile specimen geometries for weld and irradiation testing. Figure not to scale.

Table 2 shows the mechanical properties of the investigated alloys in the as-received (AR) conditions and after welding (W). Among the as-received materials, the highest strength was observed in the C35MN alloy with $\mathrm{Nb}$-addition; it was caused, most likely, by the presence of Laves phases, which could delay or slow down recrystallization. Also, even if in solid solution or the formation of small $\mathrm{Nb}$-rich carbides, $\mathrm{Nb}$ might have provided some additional hardening, compared to the rest of alloys. Yield stress for the rest of as-received materials was within $\sim 10 \%$ margin with respect to the reference $\mathrm{C} 35 \mathrm{M}$ alloy.

Ductility parameters for the as-received materials showed a close grouping around $20 \%$ for total elongation and $5-10 \%$ for uniform elongation, demonstrating the weak role of alloying on the uniform or total elongation values; the only exception was $\mathrm{C} 35 \mathrm{MN}$ alloy with lower elongation values compared to the reference. Tensile curves, Figure 11, were also similar (except C35MN) with pronounced descending part corresponding to necking. Pronounced necking (the difference between full and uniform elongations) suggests high local ductility of the materials.

Welding led to some softening for all materials; yield stress dropped to $\sim 500-560 \mathrm{MPa}$. Fracture in the welded specimens always occurred in the weldment, close to the center line. The largest yield stress value in a weldment (569 MPa) was observed for the C35MN alloy. Softening degree (the ratio of yield stress change after welding to the initial yield stress value, $\left.\Delta \sigma_{02} / \sigma_{02^{-}} \mathrm{AR}, \%\right)$ varied slightly for the investigated materials. The largest softening degree (34\%) was observed for the C35MN alloy; most likely, welding led to the dissolution of the hardening precipitation phases, which survived annealing but dissolved, at least partly, during welding.

Table 2. Mechanical properties of the modified alloys before and after welding

\begin{tabular}{|c|c|c|c|c|c|c|c|c|}
\hline Alloy & Conditions & $\begin{array}{c}\text { Yield stress, } \\
\sigma_{02}(\mathrm{MPa})\end{array}$ & $\begin{array}{c}\text { Ultimate } \\
\text { stress } \\
(\mathrm{MPa}) \\
\end{array}$ & $\begin{array}{c}\text { Uniform } \\
\text { elongation } \\
(\%) \\
\end{array}$ & $\begin{array}{c}\text { Total } \\
\text { elongation } \\
(\%) \\
\end{array}$ & $\begin{array}{l}\text { Softening } \\
\text { Degree }\end{array}$ & $\begin{array}{c}\text { Sudden } \\
\text { fracture } \\
\text { events } \\
\end{array}$ & Fracture type \\
\hline \multirow{2}{*}{ C35M } & $\mathrm{AR}$ & $627.4 \pm 13.8$ & $717.2 \pm 15$ & $12.5 \pm 0.3$ & $20.9 \pm 0.4$ & \multirow{2}{*}{$18 \%$} & - & Ductile \\
\hline & W & 515.5 & 601.6 & 4.7 & 11.4 & & - & Ductile \\
\hline \multirow{2}{*}{ C37M } & $\mathrm{AR}$ & 587.2 & 720.9 & 10.8 & 20.4 & \multirow{2}{*}{$12 \%$} & - & Ductile \\
\hline & $\mathrm{W}$ & 514.0 & 629.05 & 4.5 & 4.5 & & All spec. & Cleavage \\
\hline \multirow{2}{*}{ C35MN } & $\mathrm{AR}$ & 863.1 & 933.6 & 6.3 & 10.9 & \multirow{2}{*}{$34 \%$} & - & Ductile \\
\hline & $\mathrm{W}$ & 569.0 & 631.3 & 2.3 & 5.4 & & $\sim 50 \%$ & Cleavage \\
\hline \multirow{2}{*}{ C35M01TC } & AR & 674.4 & 755.2 & 10.7 & 17.8 & \multirow{2}{*}{$19 \%$} & - & Ductile \\
\hline & $\mathrm{W}$ & 545.8 & 623.8 & 4.9 & 12.6 & & - & D: $30 \%, C: 70 \% *$ \\
\hline \multirow{2}{*}{ C35M03TC } & $\mathrm{AR}$ & 595.3 & 701.8 & 13.2 & 22.5 & \multirow{2}{*}{$11 \%$} & - & $\mathrm{n} / \mathrm{d}$ \\
\hline & W & 528.9 & 650.9 & 5.6 & 9.1 & & - & Cleavage \\
\hline \multirow{2}{*}{ C35M10TC } & $\mathrm{AR}$ & 581.6 & 707.5 & 14.6 & 23.0 & \multirow{2}{*}{$11 \%$} & - & $\mathrm{D}: 30 \%, \mathrm{C}: 70 \% *$ \\
\hline & W & 518.8 & 683.4 & 6.8 & 12.0 & & - & $\mathrm{D}: 50 \%, \mathrm{C}: 50 \% *$ \\
\hline
\end{tabular}




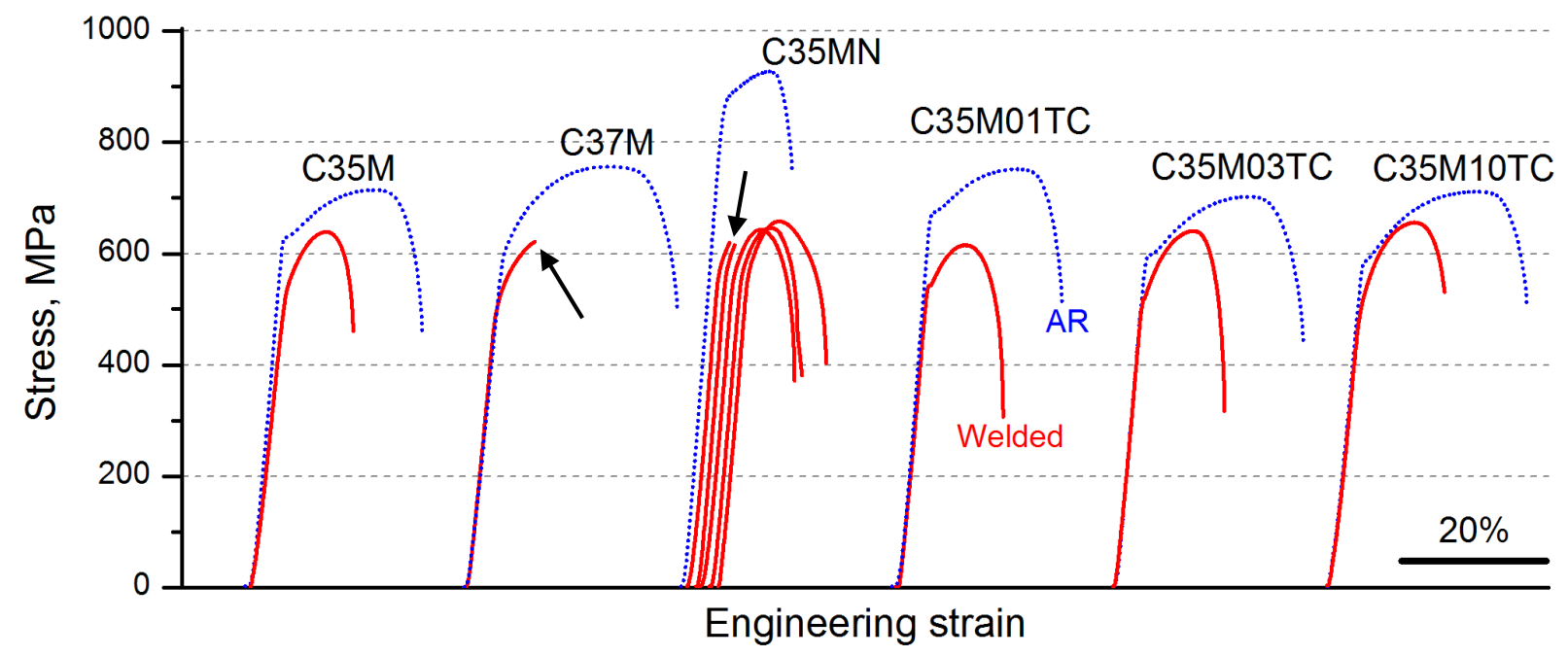

Figure 11. Representative tensile curves for the investigated material in the as-received conditions (AR, dotted blue curves) and after welding (Welded, solid red lines). Several curves are shown for the C35MN alloy to illustrate the brittle fracture cases. Black arrows point to sudden fracture events.

Whereas yield strength of the welded specimens varied slightly among the investigated materials, ductility response demonstrated pronounced changes. As follows from mechanical test results, Figure 11, the C37M alloy specimens showed unexpected fracture without neck formation and with low overall ductility, Table 2. Only one curve is given in Figure 11; however, such sudden fracture happened for all tested welded specimens of C37M alloy. Additionally, about half of the C35MN alloy specimens after welding unexpectedly fractured at small strains. It may be caused by pre-existing defects, for example, voids and small invisible cracks formed during welding. Although not observed during weldment evaluation, tiny cracks or voids even at low number densities could play the role of critical defects initiating the fracture.

Materials with TiC addition, Table 2, demonstrated very weak changes in the yield and ultimate stress levels after welding, compared to the as-received C35M alloy. No sudden fracture events were observed in the welded specimens of these alloys, indicating variability in the ductility of weldments based on the alloying branch in Figure 1 investigated.

\subsection{Fractography analysis of the tested specimens}

Figure 12 shows the typical fracture surfaces for the as-received and welded specimens. As follows from the results, all as-received alloys (both reference material and modified alloys) demonstrated a ductile fracture mechanism during tensile testing. Numerous, well-developed dimples were observed at the fracture surface, Figure 12, left column. 

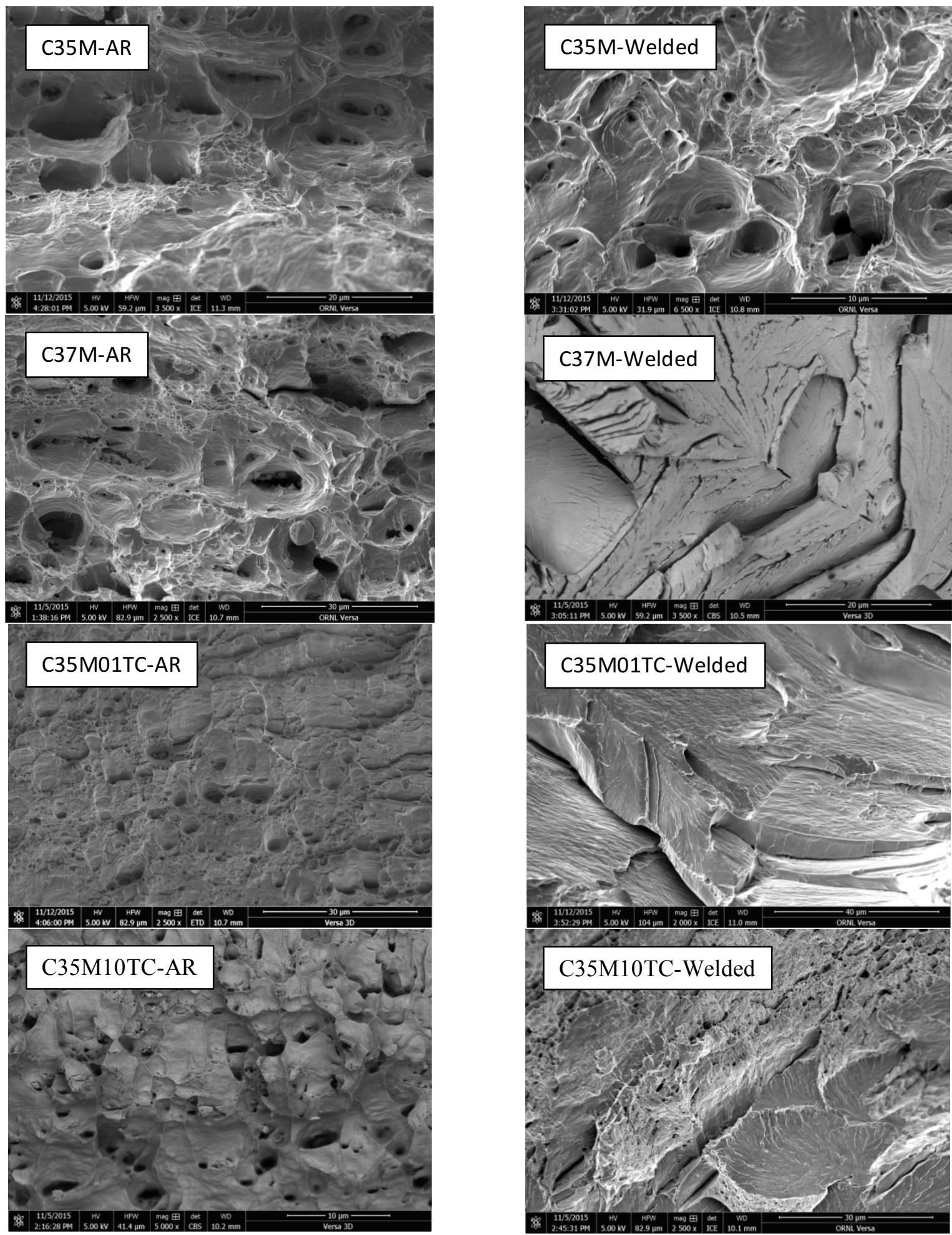

Figure 12. Representative fracture surface images for the investigated materials. Since ductile fracture was typical for all alloys in the as-received conditions, C35MN and C35M03TC were omitted from the figure. 
After welding, the C35M alloy demonstrated mostly ductile fracture; dimple height tended to decrease compared to the as-received conditions, but no cleavage spots were observed. C37M after welding had completely brittle fracture; only cleavage surface was observed without any signs of ductile dimples. Additions of $\mathrm{Nb}$ and $0.1 \% \mathrm{TiC}$ also led to the dominating cleavage fracture; no or very few ductile spots were found. These observations are summarized in Table 1, "Fracture type" column.

The behavior of alloys with TiC changed depending on the TiC-content. With TiC-amount increase, the fracture mechanism in the weldment shifted from dominating cleavage ( $70 \%$ in C35M01TC) to mixed $(50 / 50 \%)$ fracture. Interestingly, the cleavage fracture did not interfere with high local ductility and neck development in the modified alloys. Most likely, fracture occurred only after reaching some stress level, and below this threshold, the material behavior may be considered as ductile. In other words, below the critical stress level, the material should stay safe. Additional tests, focusing on fracture processes and resistance to the crack propagation are needed to shed more light on this interesting finding.

\subsection{True curves for tested specimens}

Welded specimens are complex objects that include the fusion zone, heat-affected zone, and parent (asreceived) material [30]. In this case, conventional engineering tensile curves do not represent the exact properties of the weldment and are a result the of complex interplay between areas with different properties.

To investigate the weldment behavior in more detail, local mechanical behavior was analyzed using DIC data for the welded and as-received specimens. True stress-strain curves were calculated using a common approach [31] to retrieve the real material behavior prior to and after welding. This type of curve has no ultimate stress point or uniform elongation limit. The true curves end with the specimen fracture at some critical strain/stress values. In experimental practice, the maximum strain value is limited by some level due to the limitation of the experimental method used to retrieve the true curves. For instance, for the DIC approach as the main tool, inaccuracy increases when necking begins [32]. Detailed analysis of the true curves usually includes some constitutive equations [33] or modern approaches based on the physics of plasticity [34], but this aspect was out of the present work scope.

Figure 13 shows true local stress - true strain curves representing the behavior of the as-received materials and their weldments. As follows from Figure 13, the weldments demonstrated significant local ductility; true strains reached $\sim 0.2-0.3$ or more for all investigated alloys except C37M. Nevertheless, even welded $\mathrm{C} 37 \mathrm{M}$ alloy with low engineering ductility $(\mathrm{TE}<5 \%)$ demonstrated high local true strains in the weldment.

For the reference material $(\mathrm{C} 35 \mathrm{M})$ and ME-branch alloys $(\mathrm{C} 37 \mathrm{M}$ and $\mathrm{C} 35 \mathrm{MN})$, the true curves for the weldments were shifted to the smaller stresses and appeared to have smaller deformation hardening rate. This observation reflects recrystallization processes, which eliminated the controlled structure introduced by the manufacturing process and formed large grains in the weldment. Grain size increase usually leads to the reduction in the strain hardening parameters for metallic systems [33].

Interestingly, deformation hardening rate appears to increase for the weldments with TiC-addition with the TiC-content increase. In the alloy with $1 \% \mathrm{TiC}$ (C35M10TC), the stress level in the weldment is close to the as-received material starting at a true strain level of $\sim 0.1-0.15$, Figure 13 . It may be explained, in the first iteration, by grain refinement in the C35M10TC alloy weldment, as shown in Figure 7. 


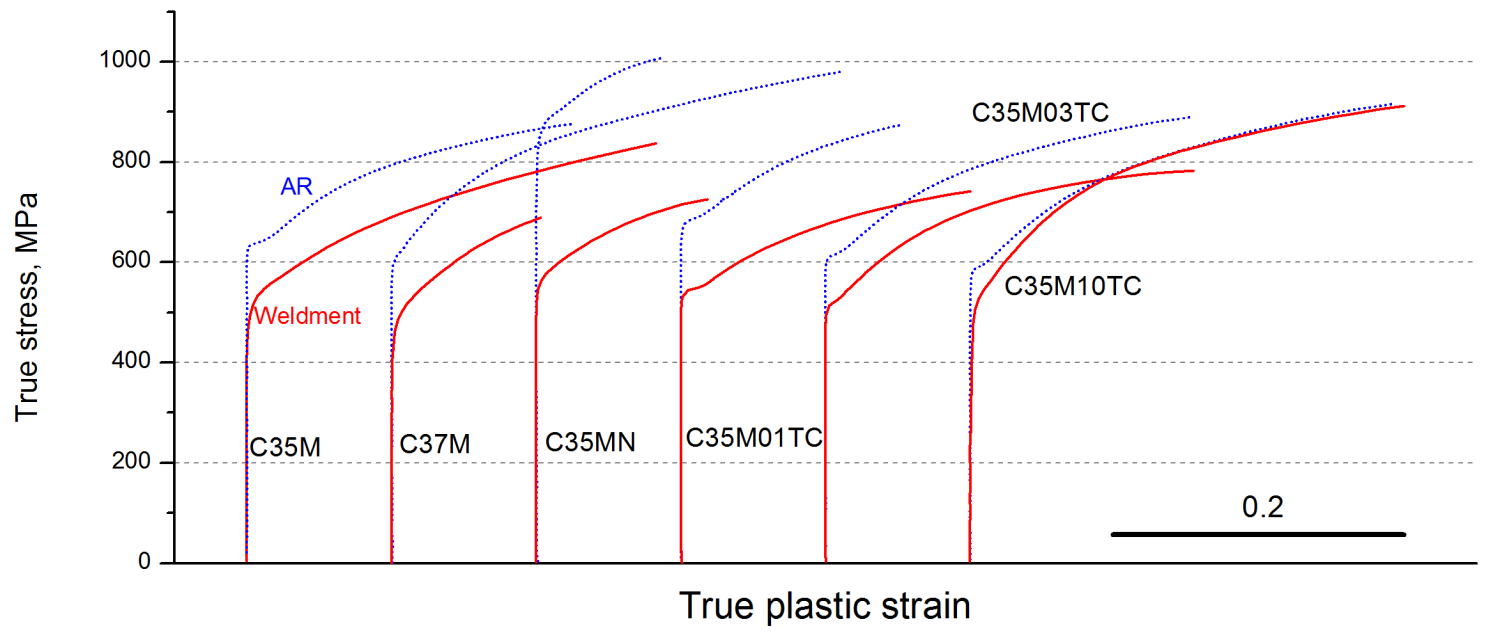

Figure 13. Representative "True stress, MPa - true plastic strain" curves for the as-received materials (AR, dash blue lines) and for the weldments (solid red lines).

\subsection{Local yield stress analysis of tested specimens}

As was mentioned above, miniature welded specimens are complex objects with multiple areas, which are expected to have different properties. Yield stress calculated from tensile diagram represents the strength of the weakest location, which is not necessarily the fusion zone or surrounding regions of the weldment. Local yield stress distribution (LYS) curves were calculated for all materials using DIC data. This approach evaluates the transition from purely elastic to the elastic-plastic behavior for each specimen point (or along the specimen gauge) using DIC images taken during the test.
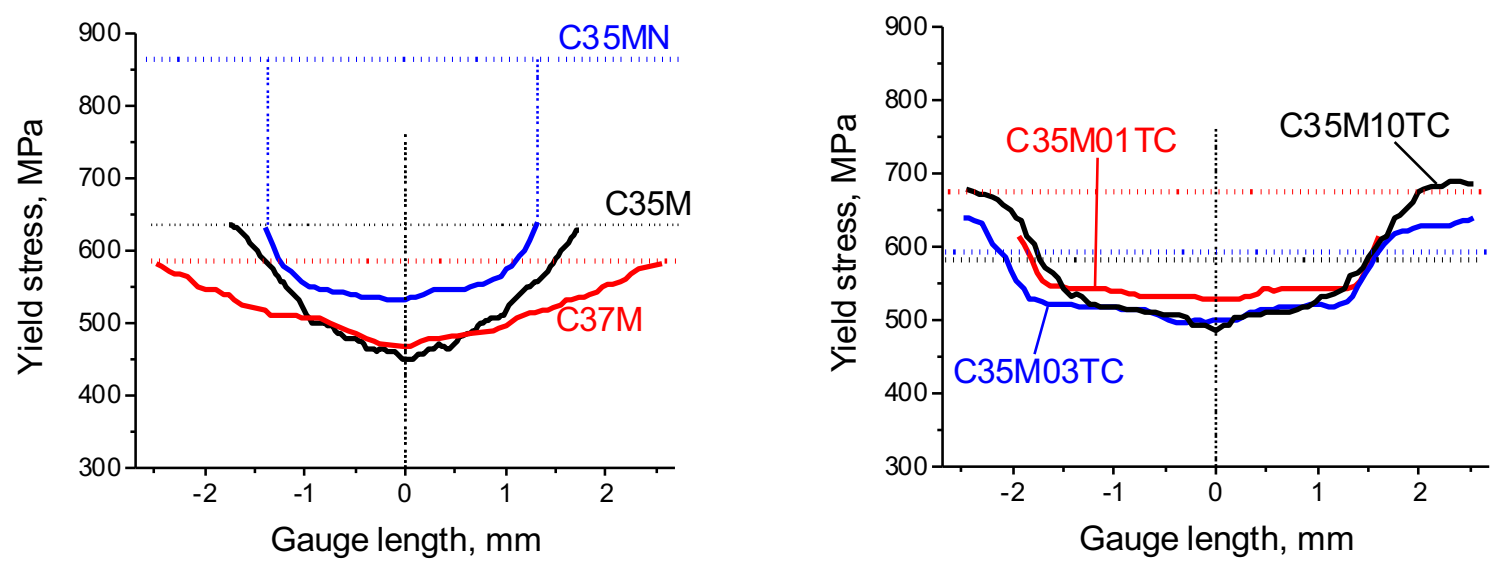

Figure 14. Yield stress distribution along the specimen gauge center line; zero corresponds to the weldment center which is also the gauge center; total gauge length is $5.036 \mathbf{~ m m}$. Solid lines show the data for the weldments; dotted lines correspond to the yield stress of bulk parent material, Table 2.

Figure 14 shows the distribution of the local yield stress along the specimen gauges. As follows from the data, in all cases, the minimum LYS values corresponded to the weldment center with the largest grains. LYS values usually increased when the distance from the weld centerline increased, but the change rate depended on the investigated alloys. For the C35M and C37M, the LYS-curves had a "U"-like shape with a smooth transition between different areas (weldment, HAZ, parent material). The C37M alloy was more 
sensitive to the thermal impact during welding; the width of the softened area was much higher compared to other alloys.

In the C35MN alloy, the plastic strain was localized in narrow, $\sim 2.5 \mathrm{~mm}$ width area (weldment and grain growth area). The HAZ area was not involved in the straining suggesting its strength was comparable to the as-received material. Most likely, the $\mathrm{Nb}$-addition in this alloy provided increased resistance to the recrystallization processes in the HAZ.

Alloys with TiC-addition also had narrow, $\sim 3 \mathrm{~mm}$, area with reduced yield stress; the transition between this area and parent (as-received) material was sharp and abrupt, compared to the smooth change in the $\mathrm{C} 35 \mathrm{M}$ and $\mathrm{C} 37 \mathrm{M}$ alloys. It may be suggested the HAZ experienced limited softening and grain growth for the alloys with TiC-addition. Moreover, LYS values in the HAZ for the C35M03 TC alloy $(+0.3 \%$ $\mathrm{TiC})$ was slightly higher, compared to the parent, non-welded material ( $\sim 630$ and $595 \mathrm{MPa}$, respectively). Welding-induced hardening in the HAZ was even more pronounced in the C35M10TC alloy $(+1.0 \%$ TiC): 680 vs. $582 \mathrm{MPa}$, respectively.

The strength (LYS) change in the HAZ is a result of several competing processes: (1) softening due to recrystallization and grain growth, (2) deformation-induced hardening due to contraction as temperature decreased after welding, and (3) aging if the material is aging sensitive. For the C35M and C37M alloys, softening dominated in the HAZ leading to the yield stress decreasing, whereas C35M03TC and C35M10TC experienced hardening. The exact behavior of C37M alloy is not clear (hardening might have occurred outside the gauge, but no softening was observed). Most likely, both $\mathrm{Nb}$ and $\mathrm{TiC}$ additions provided some resistance to the welding-induced recrystallization and softening limiting the width of the softened area.

The used specimen geometry with 5-mm gauge provided enough space to study the local behavior of the weldment; however, a longer specimen may be necessary if the HAZ properties are also of interest. For instance, the width of the HAZ area, demonstrated hardening in C35M10TC alloy, may be up to 5-6 mm from the weldment center. SS-1 geometry with 25.4-mm gauge [35] may be more beneficial in this case.

Regarding absolute yield stress in the weldment, the C35MN and C35M01TC alloys had the largest yield stress in the weldment ( $\sim 550 \mathrm{MPa})$. Summarizing the results on the weldment and HAZ width and LYS of the weldment and HAZ, one may conclude that materials with $\mathrm{TiC}$ and $\mathrm{Nb}$ additions had better resistance to the heat impact during welding. 


\section{IRRADIATION CAMPAIGN AND PRELIMINARY RESULTS OF THE POST IRRADIATION EXAMINATION}

\subsection{Description of irradiation campaign}

Detailed reports on the design and deployment of capsules for neutron irradiation of candidate $\mathrm{FeCrAl}$ alloys have been provided previously [17,18], only a brief description is provided within this report. The neutrons irradiations were designed to probe the key factors in the radiation tolerance of FeCrAl alloys and their weldments including alloy (both composition and microstructure), irradiation temperature, and damage dose. The different alloys listed in Table 1 span a range of compositions and microstructures, see Chapter 2, thereby providing these as input variables to the irradiation campaign. Three different irradiation temperatures which span a large range of temperatures were selected. These temperatures were $200^{\circ} \mathrm{C}, 330^{\circ} \mathrm{C}$, and $550^{\circ} \mathrm{C}$. It is expected that these three different temperatures exist within different regimes for prominent radiation effects: a dislocation loop dominated regime at $200^{\circ} \mathrm{C}$, a mixed dislocation loop and precipitation dominated regime at $330^{\circ} \mathrm{C}$, and softening or limited dislocation loop dominated regime at and above $550^{\circ} \mathrm{C}$ [36]. Nominal target doses in displacements per atom (dpa) were selected as $2 \mathrm{dpa}, 8 \mathrm{dpa}$, and $15 \mathrm{dpa}$. This damage dose range spans a typical lifetime accumulated dose for fuel cladding in typical commercially operating light water reactors (LWRs).

As-received and welded specimens were loaded into specially designed capsules, or "rabbits", to reach the target nominal temperatures and damage doses. Loaded specimens were in both the sub-sized SS-J2 tensile specimen configuration, Figure 10, and the ultra-miniature SS-2E tensile specimen. Details regarding the use of SS-2E specimens for mechanical testing can be found within Ref [17]. A total of 27 SS-J2 specimens and 18 SS-2E specimens of varying alloy and condition were loaded within each irradiation capsule. Hence, a total of 405 specimens are being or have been irradiated within this irradiation campaign. An additional 12 passive $\mathrm{SiC}$ thermometry samples were loaded within each capsule to validate the modeled target irradiation temperatures. A picture of the irradiation capsule, specimens, and internal components are provided in Figure 15. Capsule designs were optimized to reach the nominal target temperatures using a capsule-specimen volume average. The resulting expected temperatures are provided in Table 3.

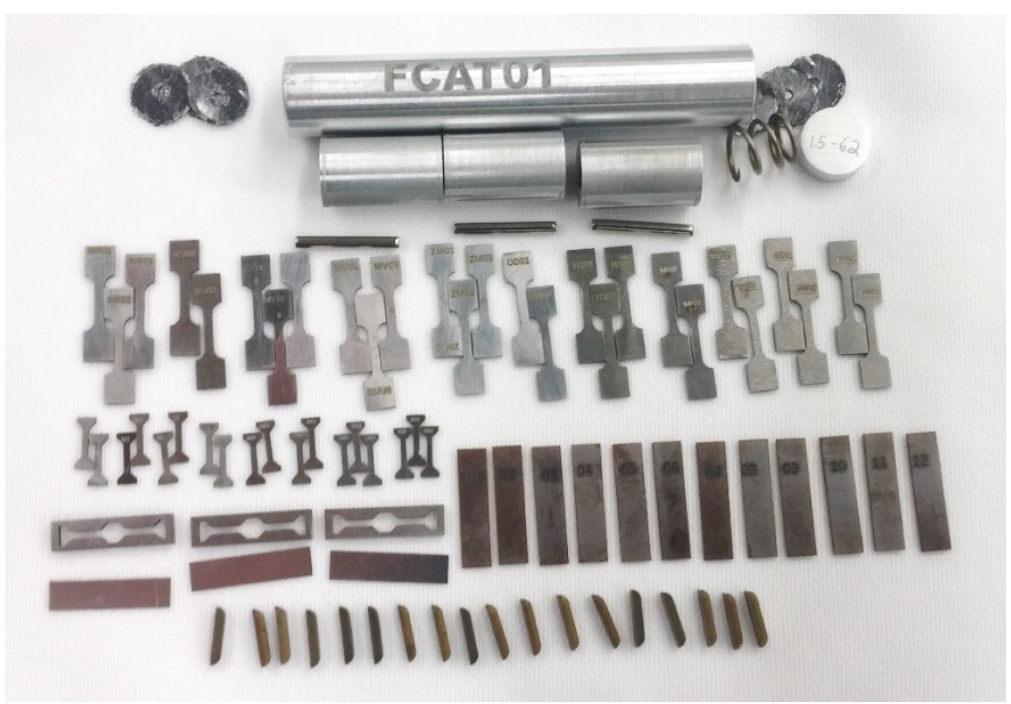

Figure 15: Internal components of the FCAT01 capsule during specimen loading. 
Table 3: Thermal analysis conditions for a mixed SS-2E and SS-J2 tensile specimens' rabbit.

\begin{tabular}{|c|c|c|c|c|c|c|}
\hline \multirow{2}{*}{$\begin{array}{c}\text { Target } \\
\text { Temperature }\end{array}$} & \multirow{2}{*}{$\begin{array}{c}\text { HFIR } \\
\text { Position }\end{array}$} & \multirow{2}{*}{$\begin{array}{c}\text { Holder } \\
\text { Diameter }\end{array}$} & \multirow{2}{*}{$\begin{array}{l}\text { Specimen } \\
\text { Location }\end{array}$} & \multicolumn{3}{|c|}{ Specimen Analysis Conditions } \\
\hline & & & & Avg. & Min. & Max. \\
\hline \multirow{3}{*}{$200^{\circ} \mathrm{C}$} & \multirow{3}{*}{ PTP 5} & \multirow{3}{*}{$9.43 \mathrm{~mm}$} & Outer & $199^{\circ} \mathrm{C}$ & $171^{\circ} \mathrm{C}$ & $242^{\circ} \mathrm{C}$ \\
\hline & & & Middle & $222^{\circ} \mathrm{C}$ & $177^{\circ} \mathrm{C}$ & $263^{\circ} \mathrm{C}$ \\
\hline & & & Inner & $235^{\circ} \mathrm{C}$ & $181^{\circ} \mathrm{C}$ & $277^{\circ} \mathrm{C}$ \\
\hline \multirow{3}{*}{$330^{\circ} \mathrm{C}$} & \multirow{3}{*}{ PTP 6} & \multirow{3}{*}{$9.28 \mathrm{~mm}$} & Outer & $314^{\circ} \mathrm{C}$ & $288^{\circ} \mathrm{C}$ & $351^{\circ} \mathrm{C}$ \\
\hline & & & Middle & $336^{\circ} \mathrm{C}$ & $292^{\circ} \mathrm{C}$ & $373^{\circ} \mathrm{C}$ \\
\hline & & & Inner & $348^{\circ} \mathrm{C}$ & $300^{\circ} \mathrm{C}$ & $386^{\circ} \mathrm{C}$ \\
\hline \multirow{3}{*}{$550^{\circ} \mathrm{C}$} & \multirow{3}{*}{ PTP 5} & \multirow{3}{*}{$9.00 \mathrm{~mm}$} & Outer & $502^{\circ} \mathrm{C}$ & $476^{\circ} \mathrm{C}$ & $543^{\circ} \mathrm{C}$ \\
\hline & & & Middle & $525^{\circ} \mathrm{C}$ & $484^{\circ} \mathrm{C}$ & $563^{\circ} \mathrm{C}$ \\
\hline & & & Inner & $537^{\circ} \mathrm{C}$ & $488^{\circ} \mathrm{C}$ & $575^{\circ} \mathrm{C}$ \\
\hline
\end{tabular}

\subsection{Status of irradiation campaign}

In general, $\mathrm{FeCrAl}$ alloys exposed to the neutron flux of the HFIR central flux trap near reactor mid-plane generate $\sim 1.8-2.0$ dpa per HFIR cycle. Hence, the number of cycles required for $2 \mathrm{dpa}, 8 \mathrm{dpa}$, and $15 \mathrm{dpa}$ are 1 cycle, 4 cycle, and 8 cycle respectively. The low-dose irradiation capsules (FCAT01, FCAT02, FCAT03) were inserted in the central flux trap of HFIR on February 12, 2016 and started irradiation at 85 MW in cycle 465 on February 23, 2016. Cycle 465 ran for 24.6 effective full power days (EFPD) at an average daily MW value of 85.13, Figure 16, with completion on March 18, 2016. The low-dose capsules were shipped to the hot cell facilities on April 29, 2016 with capsule disassembly occurring in early May 2016 and post-irradiation examination, including tensile testing and fractography, beginning in June 2016. Sufficient time had elapsed allowing for the significant radioactive decay of the SS-2E specimens for the first initial shipment of SS-2E specimens to the Low Activation Materials Development and Analysis (LAMDA) facility [37] in late June 2016.

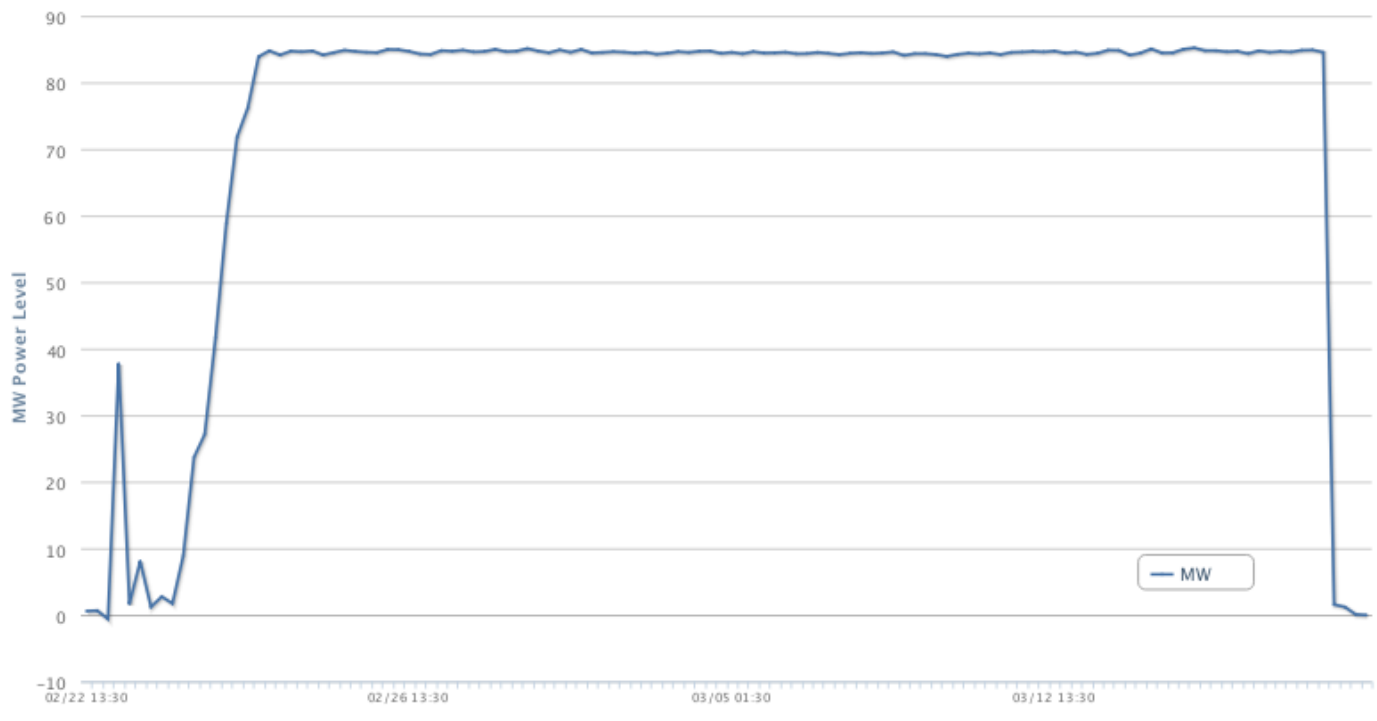

Figure 16: HFIR cycle 465 power history. 
The mid-dose specimens started irradiation in the central flux trap of HFIR on cycle 468 on September 6 , 2016. These capsules (FCAT04, FCAT05, FCAT06) are planned to run a total of 72 EFPDs. The current expected completion of the mid-dose specimens is March 17, 2017. These specimens (contained within the irradiation capsules) then can be shipped to the hot cell facilities approximately 30 days after completion of irradiation. The high-dose specimens contained in irradiation capsules FCAT06, FCAT07, and FCAT08 were inserted in the cycle after the mid-dose specimens, cycle 469, and expected to run 168 EFPD. Current HFIR forecast schedules do not run out this far in advance, but it is expected the capsules will finish irradiation within US fiscal year 2017. A summary of the status of the irradiation campaign is provided in Table 4.

Table 4. Summary of FeCrAl capsule irradiation conditions.

\begin{tabular}{|c|c|c|c|c|c|c|c|}
\hline Capsule ID & $\begin{array}{c}\text { Expected } \\
\text { EFPD }\end{array}$ & $\begin{array}{c}\text { Completed } \\
\text { EFPD }\end{array}$ & $\begin{array}{c}\text { Neutron } \\
\text { Flux } \\
\left(\mathbf{n} / \mathbf{c m}^{2} \mathbf{s}\right) \\
\mathbf{E}>\mathbf{0 . 1} \mathrm{MeV}\end{array}$ & $\begin{array}{c}\text { Neutron Fluence } \\
\quad\left(\mathbf{n} / \mathbf{c m}^{2}\right) \\
\mathbf{E}>0.1 \mathrm{MeV}\end{array}$ & $\begin{array}{c}\text { Dose Rate } \\
\text { (dpa/s) }\end{array}$ & $\begin{array}{l}\text { Dose } \\
\text { (dpa) }\end{array}$ & $\begin{array}{c}\text { Irradiation } \\
\text { Temperature } \\
\left({ }^{\circ} \mathrm{C}\right)\end{array}$ \\
\hline FCAT-01 & 22.8 & 24.6 & $1.10 \times 10^{15}$ & $2.17 \times 10^{21}$ & $9.8 \times 10^{-7}$ & 1.9 & 200 \\
\hline FCAT-02 & 22.8 & 24.6 & $1.04 \times 10^{15}$ & $2.05 \times 10^{21}$ & $9.3 \times 10^{-7}$ & 1.8 & 330 \\
\hline FCAT-03 & 22.8 & 24.6 & $1.10 \times 10^{15}$ & $2.17 \times 10^{21}$ & $9.8 \times 10^{-7}$ & 1.9 & 550 \\
\hline FCAT-04 & 72 & 48 & $1.10 \times 10^{15}$ & $9.12 \times 10^{21 *}$ & $9.8 \times 10^{-7} *$ & $8.2 *$ & $200 *$ \\
\hline FCAT-05 & 72 & 48 & $1.04 \times 10^{15}$ & $8.62 \times 10^{21 *}$ & $9.3 \times 10^{-7} *$ & $7.7 *$ & $330^{*}$ \\
\hline FCAT-06 & 72 & 48 & $1.10 \times 10^{15}$ & $9.12 \times 10^{21 *}$ & $9.8 \times 10^{-7} *$ & $8.2 *$ & $550 *$ \\
\hline FCAT-07 & 168 & 24 & $1.10 \times 10^{15}$ & $1.82 \times 10^{22} *$ & $9.8 \times 10^{-7} *$ & $16.3^{*}$ & $200^{*}$ \\
\hline FCAT-08 & 168 & 24 & $1.04 \times 10^{15}$ & $1.73 \times 10^{22 *}$ & $9.3 \times 10^{-7} *$ & $15.4^{*}$ & $330^{*}$ \\
\hline FCAT-09 & 168 & 24 & $1.10 \times 10^{15}$ & $1.82 \times 10^{22} *$ & $9.8 \times 10^{-7} *$ & $16.3^{*}$ & $550 *$ \\
\hline
\end{tabular}

*Indicates nominal target temperature

\subsection{Post-irradiation examination results}

\subsubsection{Determination of irradiation temperatures}

A significant amount of post-irradiation examination on the low dose $(<2 \mathrm{dpa})$ irradiation capsule have been completed. The first step in the PIE workflow was to determine the real (in contrast to the calculated nominal) irradiation temperatures using the passive $\mathrm{SiC}$ thermometry that were co-irradiated with in the FeCrAl specimens. The SiC thermometry samples were identified, cleaned, packaged and shipped to the LAMDA facility. Final cleaning and verification of $\mathrm{SiC}$ sample IDs were completed prior to conducting further analysis. Most samples were received in a pristine condition allowing for extensive analysis of the irradiation temperatures. A total of 5-6 SiC thermometers per irradiation capsule, 1 from 2 radial positions from each axial position, were analyzed using dilatometric analysis. The test matrix allows for the determination of both the axial and radial temperature variations within the capsule. For the low temperature irradiation capsules $\left(200^{\circ} \mathrm{C}\right.$ and $\left.330^{\circ} \mathrm{C}\right)$, dilatometric analysis was conducted up to a maximum temperature of $600^{\circ} \mathrm{C}$ at a constant ramp rate of $1{ }^{\circ} \mathrm{C} / \mathrm{min}$ and a cooling rate of $2.5^{\circ} \mathrm{C} / \mathrm{min}$ using a Netzsch $402 \mathrm{CD}$ dilatometer. For the $550^{\circ} \mathrm{C}$ capsule, the same ramp rates were used, but a maximum temperature of $900^{\circ} \mathrm{C}$ was used.

Table 5 provides the resulting dilatometric analysis of the selected $\mathrm{SiC}$ thermometry samples. It should be noted that the $\mathrm{SiC}$ thermometry is expected to have higher reported temperatures than the nominal specimen average irradiation temperatures as the SiC thermometry specimens are situated within the inner radius of the irradiation capsule while the specimens are closest to the capsule outer diameter. Table 5 shows that the determined irradiation temperatures are within the expected range of irradiation 
temperatures for all three capsules. In the case of the $330^{\circ} \mathrm{C}$ and $550^{\circ} \mathrm{C}$ irradiations, the reported temperatures versus the expected temperatures showed a variance of $\sim 15^{\circ} \mathrm{C}$. The $200^{\circ} \mathrm{C}$ irradiations had a larger variance, $\sim 47.5^{\circ} \mathrm{C}$. This indicates that the irradiation temperature of the samples was significantly lower than the expected temperature of $219^{\circ} \mathrm{C}$. It should also be noted that due to the increased contact resistances of the SS-2E specimen geometry and modules, $\mathrm{SiC}$ specimens coming from these regions consistently reported higher temperatures than the regions containing SS-J2 specimens and can be a systematic source of error between the radiation behavior of the two different tensile specimen geometries. Furthermore, Table 5 also indicates axial variation in the irradiation temperature which could result in different alloys having slight variations in their irradiation temperature. Unfortunately, these effects cannot be erased when using standard, non-instrumented, drop-in capsule irradiations within the central flux trap of the HFIR. However, in general the temperature control over the course of the irradiation is still quite good and any observed temperature excursions from the target temperature remain within the varying expected regimes (i.e. dislocation dominate regiment at $\sim 200^{\circ} \mathrm{C}$ ). Hence, the irradiated samples remain valuable experiments for determining the radiation tolerance of the developed $\mathrm{FeCrAl}$ alloys and their weldments.

Table 5: Results of dilatometric analysis of SiC thermometry bars contained within irradiated capsules.

\begin{tabular}{|c|c|c|c|c|c|c|c|}
\hline \multicolumn{6}{|c|}{ Experimental Values } & \multicolumn{2}{|c|}{ Modeled Values } \\
\hline Capsule & Specimen & Minimum & Median & Maximum & $\begin{array}{l}\text { Average } \\
\text { Median }\end{array}$ & $\begin{array}{c}\text { Average } \mathrm{SiC} \\
\text { Specimen }\end{array}$ & $\begin{array}{c}\text { Average SS-J2 } \\
\text { Specimen }\end{array}$ \\
\hline ID & ID & $\begin{array}{l}\text { Temp. } \\
\left({ }^{\circ} \mathrm{C}\right)\end{array}$ & $\begin{array}{c}\text { Temp. } \\
\left({ }^{\circ} \mathrm{C}\right)\end{array}$ & $\begin{array}{l}\text { Temp. } \\
\left({ }^{\circ} \mathrm{C}\right)\end{array}$ & Temp. $\left({ }^{\circ} \mathrm{C}\right)$ & Temp. $\left({ }^{\circ} \mathrm{C}\right)$ & Temp. $\left({ }^{\circ} \mathrm{C}\right)$ \\
\hline \multirow{6}{*}{$\begin{array}{c}\text { FCAT } \\
- \\
01\end{array}$} & 02 TOP & 178.5 & 169.2 & 229.8 & & \multirow{6}{*}{242} & \multirow{6}{*}{219} \\
\hline & 04 TOP & 192.2 & 204.3 & 229.0 & $186.8 \pm 24.8$ & & \\
\hline & 06 MID & 186.8 & 143.4 & 235.0 & \multirow{2}{*}{$180.9 \pm 53.0$} & & \\
\hline & $08 \mathrm{MID}$ & 198.1 & 218.4 & 239.6 & & & \\
\hline & $10 \mathrm{BOT}$ & 235.1 & 237.4 & 259.1 & 237.4 & & \\
\hline & Average & \multicolumn{4}{|c|}{$194.5 \pm 37.9$} & & \\
\hline \multirow{7}{*}{$\begin{array}{c}\text { FCAT } \\
- \\
02\end{array}$} & 14 TOP & 346.2 & 358.1 & 372.5 & & \multirow{7}{*}{347} & \multirow{7}{*}{333} \\
\hline & 16 TOP & 359.9 & 383 & 405.7 & $3 / 0.0 \pm 17.0$ & & \\
\hline & 18 MID & 336.4 & 345.2 & 368.2 & $3640+270$ & & \\
\hline & 20 MID & 394.1 & 384.6 & 402.1 & \multirow{4}{*}{$355.5 \pm 36.7$} & & \\
\hline & $22 \mathrm{BOT}$ & 337.9 & 329.5 & 342.4 & & & \\
\hline & $24 \mathrm{BOT}$ & 369.9 & 381.4 & 403.1 & & & \\
\hline & Average & & 363 & $6 \pm 23.1$ & & & \\
\hline \multirow{7}{*}{$\begin{array}{c}\text { FCAT } \\
- \\
03\end{array}$} & 26 TOP & 450.1 & 524.3 & 571.5 & 55 & \multirow{7}{*}{568} & \multirow{7}{*}{521} \\
\hline & $28 \mathrm{TOP}$ & 635.0 & 589.1 & 601.1 & (50. & & \\
\hline & 30 MID & 517.7 & 551.0 & 574.5 & $549^{\circ}+2$ & & \\
\hline & 32 MID & 529.4 & 548.3 & 534.2 & 列 & & \\
\hline & $34 \mathrm{BOT}$ & 488.4 & 573.1 & 597.6 & $590>->$ & & \\
\hline & $36 \mathrm{BOT}$ & 575.7 & 607.3 & 603.7 & $390.2 \pm 24.2$ & & \\
\hline & Average & \multicolumn{4}{|c|}{$559.4 \pm 28.1$} & & \\
\hline
\end{tabular}

\subsubsection{Irradiation-induced $\alpha^{\prime}$ precipitation}

Preliminary microstructural investigations have begun on the low dose irradiated specimens. Of primary interest is the formation of dislocation loop structures and the precipitation of the $\alpha$ ' phase as these have been determined as dominate microstructural features contributing to the change in mechanical properties 
in model FeCrAl alloys [22]. Atom probe tomography (APT) has been used to investigate the $\alpha$ ' phase within this study. Following tensile testing of the C35M SS-2E tensile specimens (described in the following section), one half of the broken specimen was selected for polishing and mounting prior to focused ion beam (FIB) preparation. In the case of FIB preparation within the HAZ and fusion zone, nontested (fractured) tensile specimens were used.

FIB prepared APT specimens were characterized using a Cameca Instruments LEAP 4000X HR instrument running in laser-mode with a pulse frequency of $200 \mathrm{kHz}$, laser pulse energy of $50 \mathrm{pJ}$, and a detection rate of 0.005-0.02 atoms/pulse. Reconstruction of the APT data was completed using Cameca's Integrated Visualization and Analysis Software (IVAS) version 3.6.8. Currently, only the reconstruction of the base material of the $\mathrm{C} 35 \mathrm{M}$ alloy irradiated to $1.8 \mathrm{dpa}$ near $364^{\circ} \mathrm{C}$ has been completed, although analysis on other conditions are ongoing. Figure 17 shows the resulting reconstruction. The $\alpha^{\prime}$ is a Cr-rich phase and hence can be represented using a $\mathrm{Cr}$ concentration isosurface. Figure 17 indicates the significant precipitation of the $\alpha$ ' phase within the base material of the $\mathrm{C} 35 \mathrm{M}$ alloy after irradiation near $364^{\circ} \mathrm{C}$ after $1.8 \mathrm{dpa}$ of neutron exposure. This initial finding indicates that even though the $\mathrm{C} 35 \mathrm{M}$ alloy exists close to the nominal, literature-based $\alpha$ - $\alpha$ ' phase boundary, as shown in Figure 2, that at these lower temperatures and irradiation conditions significant precipitation of the $\alpha^{\prime}$ phase can still occur. Further analysis is ongoing including the determination on whether the additional $\mathrm{Al}$ in the $\mathrm{C} 37 \mathrm{M}$ alloy can mitigate or retard the precipitation of $\alpha^{\prime}$ in the same irradiation conditions as the data shown for $\mathrm{C} 35 \mathrm{M}$ in Figure 17.

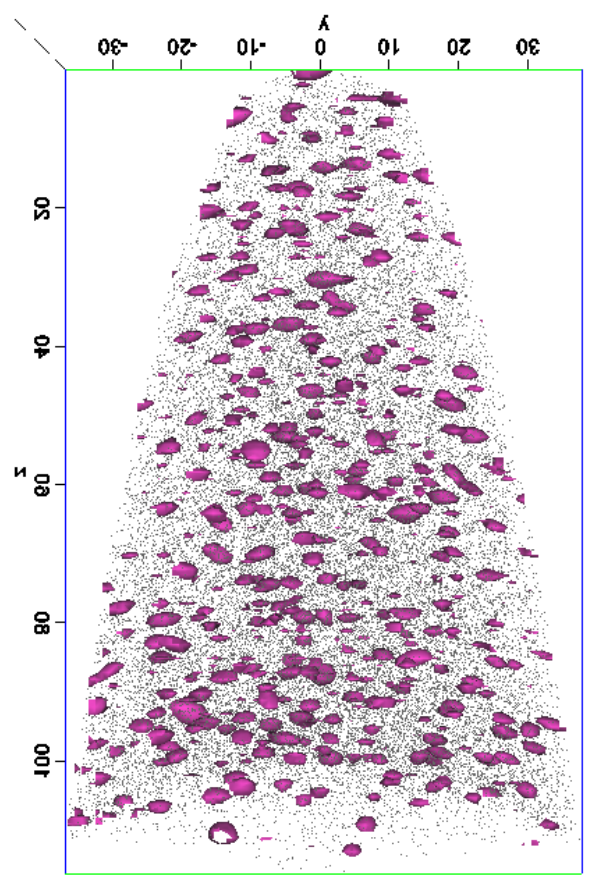

Figure 17. APT reconstruction of the $\mathrm{C} 35 \mathrm{M}$ alloy irradiated to 1.8 dpa near $364^{\circ} \mathrm{C}$. $\alpha^{\prime}$ precipitates are shown using a $\mathrm{Cr}$ concentration isosurface $(25$ at.\%). Black dots are $2 \%$ of the detected Fe atoms. Figure scale is in $\mathbf{n m}$.

\subsubsection{Mechanical properties after low dose neutron irradiation}

Mechanical tests on both the SS-J2 and SS-2E tensile specimen configurations have been completed at room temperature. For the SS-J2 tensile specimens, all compositions and irradiation conditions have been tested while only tensile tests on the C35M alloy for all conditions have been completed for the SS-2E 
tensile specimens. Further tests of other alloys in the SS-2E condition have not been completed due to the relatively high radiological activity of the specimens necessitating a graded approach in the test matrix for these configurations as they are tested out of the hot cell.

Both specimen configurations were tested using shoulder loading with a nominal rate of $\sim 10^{-3} \mathrm{~s}^{-1}$. SS-J2 specimens had no post-irradiation surface preparation while SS-2E specimens were mechanically polished followed by light electropolishing to remove any surface deformation. Electropolishing resulted in 10-20 $\mu \mathrm{m}$ of surface removed on each side. SS-J2 specimens were tested in a hot cell facility that did not facilitate the use of sophisticated high-resolution cameras needed for digital image correlation (DIC) analysis. As the SS-2E specimens were tested in a low radiological threat facility, DIC could be applied to these specimens. Hence, SS-2E specimens were painted with a random speckle pattern to provide optical, non-contact strain measurements during tensile tests. Strain-field and true stress-strain curves were determined using VIC2D commercial software and a custom program using common digital image correlation (DIC) algorithms. Tensile tests for the SS-J2 specimens in the as-received and irradiated states were performed using an Instron universal test machine at room temperature. Tensile tests for SS-2E specimens were performed using an MTS Insight 2-52 one-column tensile screw machine at room temperature.

Table 6 summarizes the mechanical properties of both the SS-J2 and SS-2E specimens tested as part of the PIE. For tests completed to date, the SS-J2 and SS-2E specimens show reasonable agreement with variation in the yield and ultimate stress below $10 \%$. This variance, $\sim 10 \%$, is within the expected experimental error band for $\mathrm{FeCrAl}$ alloys as there are irradiation temperature gradients within the capsules, Table 5, as well as some variation in the mechanical properties when samples are extracted from different locations within the same FeCrAl sheet product. It should be noted the large variance between the two specimen geometries for the $\mathrm{C} 35 \mathrm{M}$ welded specimen irradiated to $364^{\circ} \mathrm{C}$. It is anticipated this variation is due to misidentification of either specimen geometry and additional testing is underway to rectify this issue.

All base alloys generally performed in the same manner when irradiated at $364^{\circ} \mathrm{C}$ and below. Alloys irradiated in these conditions showed increases in the yield strength which was correlated to reduction in the ductility of the material and the magnitude of this response scaled inversely with irradiation temperatures. In most cases, the base alloys showed radiation-induced softening when irradiated to $559^{\circ} \mathrm{C}$. Weldments, on the other hand, showed drastically different behavior. When irradiated to $559^{\circ} \mathrm{C}$ the tensile properties remained like that of the as-received weldments. This difference within the $559^{\circ} \mathrm{C}$ irradiation condition could be the result of recrystallization within the base metal, an effect that would not happen within the fusion zone of the welded specimens. The lower irradiation temperatures caused the weldments to have sudden fracture events with the failure occurring within the elastic regime of the tensile test. Fractography has been performed on the SS-J2 specimens to determine if the sudden fracture events were the result of a fully brittle, cleavage-like fracture. A summary of this analysis is also provided in Table 6, further details can be found in Ref [19].

The overall mechanical properties remain consistent with the literature on similar materials irradiated to similar conditions. For example, ferritic high-chromium $\mathrm{FeCr}$ alloys show pronounced hardening below $1 / 3$ of the melting temperature. The two lower irradiation temperatures in this study are within this regime and show significant increase in the yield strength and decrease in ductility after irradiation to 1.8-1.9 dpa. The future mid-dose and high-dose irradiation capsules will provide further insight into the irradiation response of $\mathrm{FeCrAl}$ alloys with a focus on the irradiation dose response.

Further information on the mechanical properties of the irradiated specimens can be determined from the DIC analysis on the SS-2E samples. For example, Figure 18 shows the strain distribution along the gauge length of the $\mathrm{C} 35 \mathrm{M}$ base metal specimens irradiated to $364^{\circ} \mathrm{C}$ and $559^{\circ} \mathrm{C}$. In the case of the $364^{\circ} \mathrm{C}$ 
irradiated condition, the specimen showed uniform strain with weak localization near the specimen head when the load was near the yield stress of the specimen. Further straining caused uniform strain distribution along the specimen gauge until necking occurred. For the $\mathrm{C} 35 \mathrm{M}$ base material irradiated to $559^{\circ} \mathrm{C}$ the specimen showed no radiation hardening and plastic strain occurred in a uniform manner.

Table 6. Mechanical properties for SS-2E and SS-J2 specimens

\begin{tabular}{|c|c|c|c|c|c|c|c|c|c|c|c|c|}
\hline \multirow[b]{2}{*}{ Alloy } & \multirow{2}{*}{$\begin{array}{c}\text { Irr. } \\
\text { Tem., } \\
{ }^{\circ} \mathbf{C}\end{array}$} & \multirow{2}{*}{$\begin{array}{c}\text { Irr. } \\
\text { dose, } \\
\text { dpa }\end{array}$} & \multicolumn{4}{|c|}{ SS-J2 geometry (testing at the hot cell) } & \multicolumn{4}{|c|}{ SS-2E (Miniature specimen) } & \multirow{2}{*}{$\begin{array}{l}\text { Sudden } \\
\text { Fracture }\end{array}$} & \multirow{2}{*}{$\begin{array}{c}\text { Fracture } \\
\text { Type }\end{array}$} \\
\hline & & & $\begin{array}{l}\text { YS, } \\
\text { MPa }\end{array}$ & $\begin{array}{l}\text { UTS, } \\
\text { MPa }\end{array}$ & UE, \% & TE \% & $\begin{array}{l}\text { YS, } \\
\text { MPa }\end{array}$ & $\begin{array}{l}\text { UTS, } \\
\text { MPa }\end{array}$ & $\begin{array}{c}\text { UE, } \\
\%\end{array}$ & $\begin{array}{l}\text { TE } \\
\%\end{array}$ & & \\
\hline C35M10TC & N/A & $\mathrm{N} / \mathrm{A}$ & 574 & 705 & 16.3 & 25.2 & - & - & - & - & - & - \\
\hline C35M10TC & 195 & 1.9 & 1298 & 1300 & 0.0 & 5.5 & - & - & - & - & yes & - \\
\hline C35M10TC & 364 & 1.8 & 1108 & 1120 & 0.9 & 7.0 & - & - & - & - & - & mixed \\
\hline C35M10TC & 559 & 1.9 & 559 & 718 & 13.9 & 19.8 & - & - & - & - & - & - \\
\hline C35M10TC - welded & N/A & N/A & 496 & 645 & 8.6 & 16.0 & - & - & - & - & - & - \\
\hline C35M10TC - welded & 195 & 1.9 & 902 & 902 & 0.0 & 0.0 & - & - & - & - & yes & - \\
\hline C35M10TC - welded & 364 & 1.8 & 944 & 958 & 0.4 & 0.4 & - & - & - & - & yes & cleavage \\
\hline C35M10TC - welded & 559 & 1.9 & 546 & 720 & 9.3 & 13.7 & - & - & - & - & - & - \\
\hline C35M & N/A & N/A & 631 & 719 & 11.6 & 19.5 & - & - & - & - & - & - \\
\hline C35M & 195 & 1.9 & 1316 & 1316 & 0.0 & 2.6 & - & - & - & - & - & mixed \\
\hline C35M & 364 & 1.8 & 903 & 944 & 4.2 & 11.5 & 914 & 937 & 2.7 & 10.4 & - & ductile \\
\hline C35M & 559 & 1.9 & 585 & 725 & 12.6 & 20.4 & 602 & 734 & 12.3 & 20.8 & - & ductile \\
\hline C35M - welded & N/A & N/A & 497 & 568 & 3.7 & 10.6 & - & - & - & - & - & - \\
\hline C35M - welded & 195 & 1.9 & 941 & 941 & 0.0 & 0.0 & - & - & - & - & yes & cleavage \\
\hline C35M - welded & 364 & 1.8 & 923 & 926 & 0.4 & 0.8 & 625 & 703 & 4 & 12.1 & & cleavage \\
\hline C35M - welded & 559 & 1.9 & 423 & 511 & 5.7 & 10.8 & 442 & 545 & 6.3 & 14.5 & - & ductile \\
\hline C37M & N/A & $\mathrm{N} / \mathrm{A}$ & 645 & 806 & 13.7 & 23.7 & - & - & - & - & - & - \\
\hline C37M & 195 & 1.9 & 1083 & 1089 & 0.4 & 6.1 & - & - & - & - & - & mixed \\
\hline C37M & 364 & 1.8 & 949 & 983 & 1.9 & 9.6 & - & - & - & - & - & ductile \\
\hline C37M & 559 & 1.9 & 553 & 711 & 13.4 & 24.0 & - & - & - & - & - & ductile \\
\hline C37M - welded & 195 & 1.9 & 514 & 514 & 0.0 & 0.0 & - & - & - & - & - & cleavage \\
\hline C37M - welded & 364 & 1.8 & 890 & 890 & 0.0 & 0.0 & - & - & - & - & yes & cleavage \\
\hline C37M - welded & 559 & 1.9 & 502 & 584 & 2.3 & 2.3 & - & - & - & - & yes & cleavage \\
\hline C35MN & N/A & N/A & 923 & 982 & 4.6 & 8.4 & - & - & - & - & - & - \\
\hline C35MN & 195 & 1.9 & 1276 & 1282 & 0.3 & 4.5 & - & - & - & - & - & - \\
\hline C35MN & 364 & 1.8 & 982 & 1059 & 3.5 & 7.9 & - & - & - & - & - & - \\
\hline C35MN & 559 & 1.9 & 722 & 821 & 9.9 & 15.4 & - & - & - & - & - & - \\
\hline C35MN - welded & N/A & $\mathrm{N} / \mathrm{A}$ & 554 & 627 & 2.2 & 2.3 & - & - & - & - & - & - \\
\hline C35MN - welded & 195 & 1.9 & 927 & 961 & 0.8 & 1.0 & - & - & - & - & yes & \\
\hline C35MN - welded & 364 & 1.8 & 864 & 864 & 0.0 & 0.0 & - & - & - & - & - & - \\
\hline C35MN - welded & 559 & 1.9 & 650 & 768 & 2.5 & 2.6 & - & - & - & - & - & - \\
\hline
\end{tabular}


DIC analysis of the welded specimens showed dramatically different behavior. For example, the C35M welded specimen irradiated to $1.9 \mathrm{dpa}$ at $559^{\circ} \mathrm{C}$ showed non-uniform strain distribution after yielding, Figure 19. Figure 19 shows the formation of two local strain maximums that are within the probable region of the HAZs. With increasing strain, the strain localized within one of these maximums causes necking and eventually specimen failure. This result would suggest that the microstructural changes that form after welding are contributing to the overall performance of the FeCrAl weldments after irradiation.
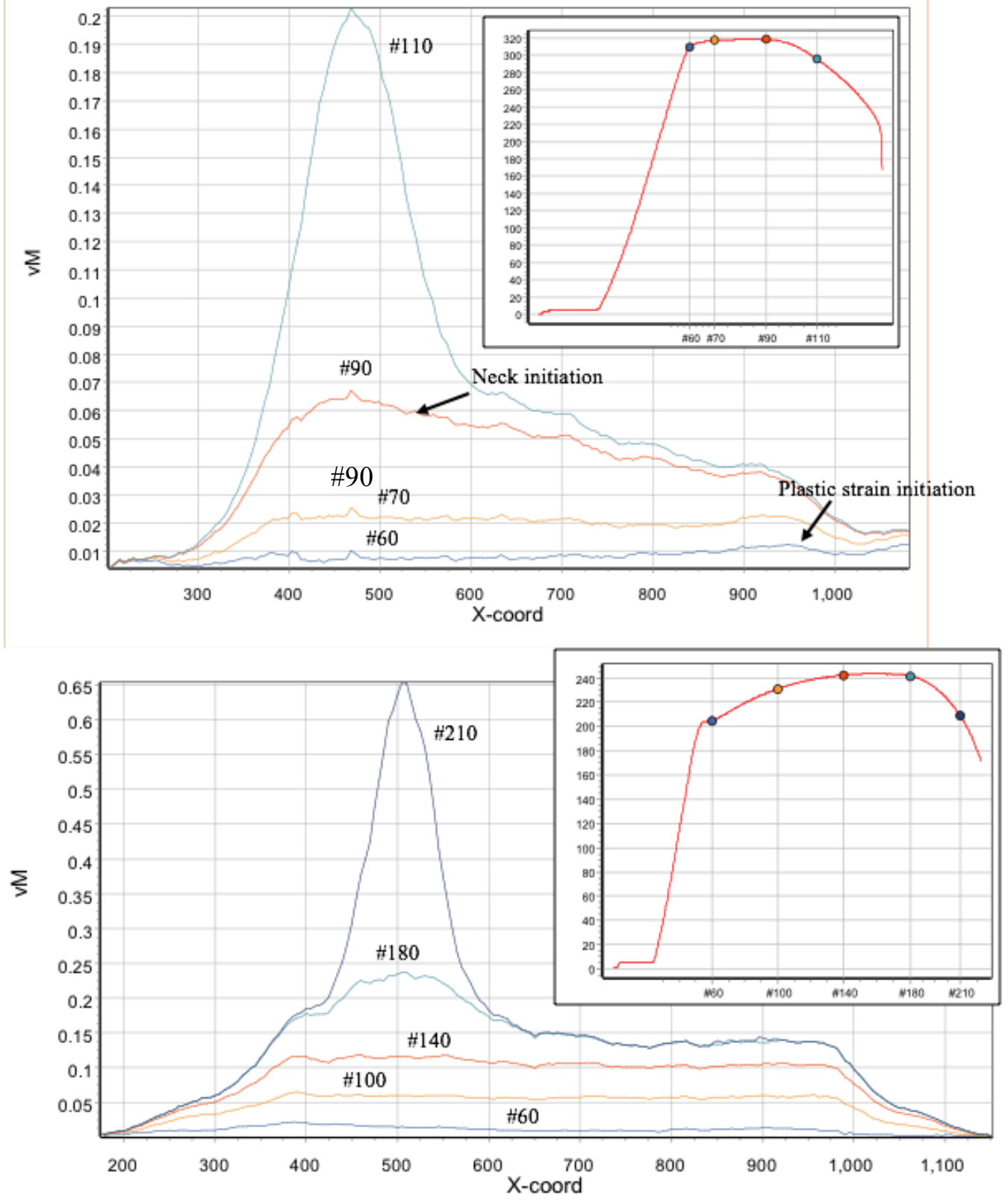

Figure 18. Strain distribution along the gauge for the $\mathrm{C} 35 \mathrm{M}$ specimens irradiated to $364^{\circ} \mathrm{C}$ (top) and $559^{\circ} \mathrm{C}$ (bottom). The inserted diagram on the right demonstrates the tensile diagram and the location of the DIC frames. The main plot shows von Mises strain (vM); Green-Lagrange tensor 
was employed. The results may be expressed using any strain metric (engineering strain or true strain); however, Green-Lagrange strain definition is the most common one for DIC.

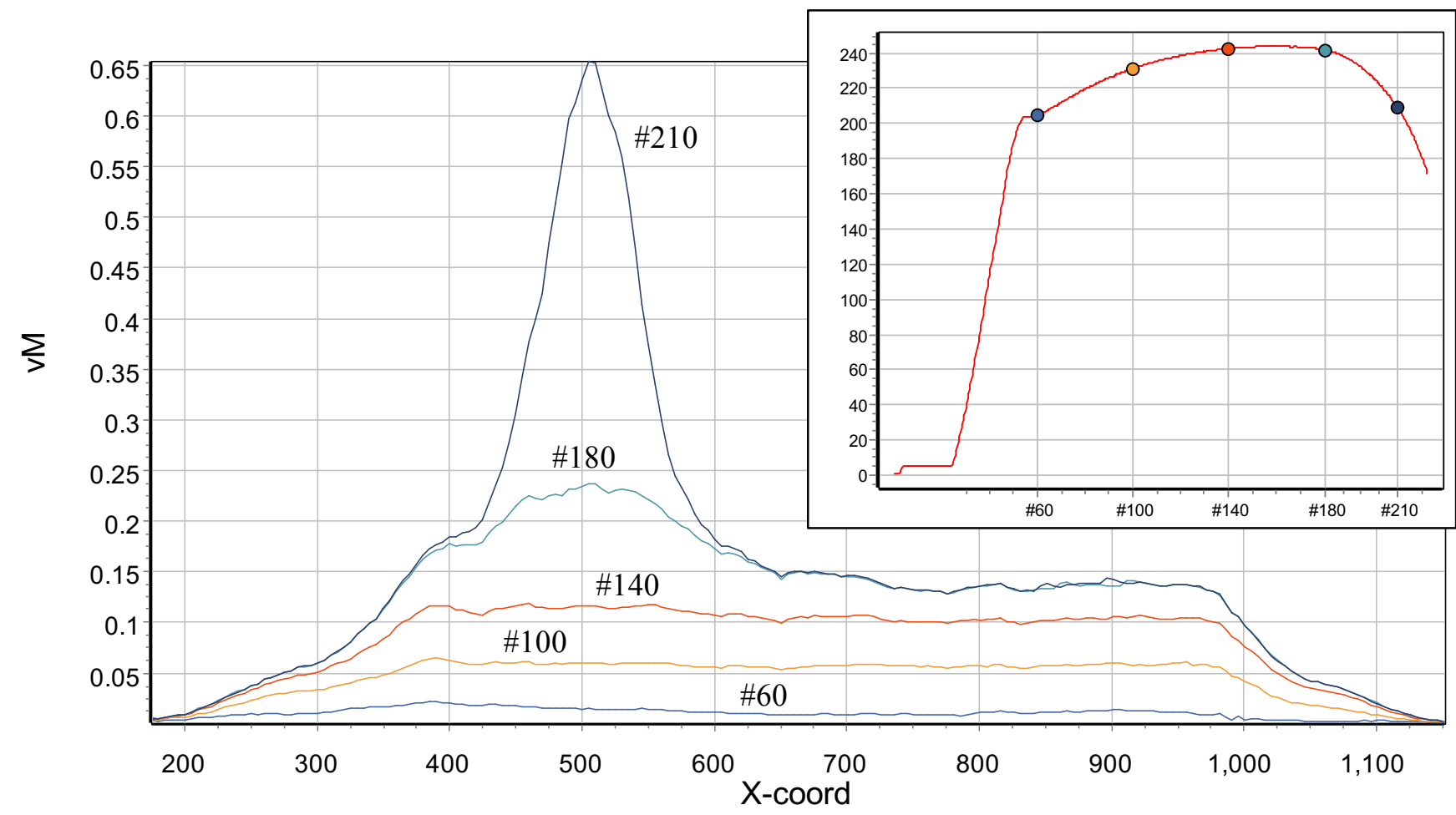

Figure 19. Strain distribution (von Mises strain, vM, developed from Green-Lagrange tensor) along the gauge for the $\mathrm{C} 35 \mathrm{M}$ weldment irradiated at $559^{\circ} \mathrm{C}$ to $1.9 \mathrm{dpa}$. The inserted diagram at the right demonstrates the tensile curve and the location of the DIC frames (\#60, \#100, etc.).

\section{CONCLUSIONS}

The results and discussion presented in the present report provide a brief overview of the program currently in place focused on optimizing both the microstructure and chemistry of the FeCrAl alloy class to obtain the necessary properties and performance for nuclear power applications including weldability, thermal stability, and radiation tolerance. Key activities have included the development of seven unique $\mathrm{FeCrAl}$ alloys, all designed to increase the weldability and radiation tolerance of the FeCrAl alloy class. Pre-irradiation characterization has indicated the beneficial role of precipitate additions into the $\mathrm{FeCrAl}$ matrix including grain refinement and reduced grain sizes within the fusion zone of laser-based weldments. An on-going irradiation campaign to test the radiation tolerance of both the base metal and weldment has shown significant progress. All capsules have begun neutron irradiation with the lowest dose capsules (FCAT01, FCAT02, FCAT03) beginning preliminary PIE. These PIE efforts have shown generally good agreement between expected irradiation temperatures and the nominal irradiation temperatures determined using passive $\mathrm{SiC}$ thermometry techniques. Mechanical testing of the irradiated specimens in both the SS-J2 and SS-2E tensile specimen configuration have shown radiation induced hardening and embrittlement at and below irradiation temperatures of $364^{\circ} \mathrm{C}$. Close matching between the strength and ductility parameters between the SS-J2 and SS-2E tensile specimen configurations have proven the use of the ultra-miniature SS-2E tensile specimen geometry for rapid screening of mechanical properties of neutron irradiated metallic materials. Furthermore, this novel geometry has permitted the use of advanced mechanical testing techniques such as DIC, thereby providing new insights into the 
deformation mechanics of ferritic alloys after low dose neutron irradiation. This report highlights the significant strides made to advance the FeCrAl alloy class for NPPs use but further development is needed before full commercialization of this alloy class can be realized.

\section{REFERENCES}

[1] K.A. Terrani, S.J. Zinkle, L.L. Snead, Advanced oxidation-resistant iron-based alloys for LWR fuel cladding, J. Nucl. Mater. 448 (2013) 420-435. doi:10.1016/j.jnucmat.2013.06.041.

[2] K.A. Terrani, Y.J. Kim, B.A. Pint, Uniform Corrosion of Model FeCrAl Alloys in LWR Coolants, 2015 Am. Nucl. Soc. Annu. Meet. (2015).

[3] B.A. Pint, S. Dryepondt, K.A. Unocic, D.T. Hoelzer, Development of ODS FeCrAl for compatibility in fusion and fission energy applications, Jom. 66 (2014) 2458-2466. doi:10.1007/s11837-014-1200-z.

[4] B.A. Pint, K.A. Terrani, M.P. Brady, T. Cheng, J.R. Keiser, High temperature oxidation of fuel cladding candidate materials in steam-hydrogen environments, J. Nucl. Mater. 440 (2013) 420 427. doi:10.1016/j.jnucmat.2013.05.047.

[5] M. Snead, L.L. Snead, K.A. Terrani, K.G. Field, A. Worrall, K.R. Robb, et al., Technology Implementation Plan ATF FeCrAl Cladding for LWR Application, Oak Ridge National Laboratory, Oak Ridge, TN, 2014.

[6] B.A. Pint, K.A. Unocic, K.A. Terrani, The effect of steam on the high temperature oxidation behavior of alumina-forming alloys, Mater. High Temp. 32 (2014) 28-35.

[7] Y. Yamamoto, B.A. Pint, K.A. Terrani, K.G. Field, Y. Yang, L.L. Snead, Development and property evaluation of nuclear grade wrought $\mathrm{FeCrAl}$ fuel cladding for light water reactors, $\mathrm{J}$. Nucl. Mater. 467 (2015) 703-716. doi:10.1016/j.jnucmat.2015.10.019.

[8] E.A. Little, D.A. Stow, Void-swelling in irons and ferritic steels, J. Nucl. Mater. 87 (1979) 25-39.

[9] B.A. Pint, K.A. Terrani, Y. Yamamoto, L.L. Snead, Material Selection for Accident Tolerant Fuel Cladding, Metall. Mater. Trans. E. 2 (2015) 190-196.

[10] W. Chubb, S. Alfant, A.A. Bauer, E.J. Jablonowski, F.R. Shober, R.F. Dickerson, Constitution, metallurgy, and oxidation resistance of iron-chromium-aluminum alloys: BMI-1298, (1958).

[11] Y. Yamamoto, K.A. Terrani, Optimized Gen-II FeCrAl cladding production in large quantity for campaign testing, ORNL/TM-2016/227. (2016).

[12] Y. Yamamoto, M.N. Gussev, B.K. Kim, T.S. Byun, Optimized properties on base metal and thinwalled tube of Generation II ATF FeCrAl, Oak Ridge National Laboratory, 2015.

[13] J.R. Regina, J.N. Dupont, A.R. Marder, The effect of chromium on the weldability and microstructure of Fe-Cr-Al weld cladding, Weld. J. 86 (2007) 170-178.

[14] J.N. Dupont, J.R. Regina, K. Adams, Improving the weldability of fecral weld overlay coatings, Foss. Energy Mater. Conf. (2007) 131-137.

[15] K.G. Field, M.N. Gussev, X. Hu, Y. Yamamoto, Preliminary Results on FeCrAl Alloys in the Asreceived and Welded State Designed to Have Enhanced Weldability and Radiation Tolerance, 
ORNL/TM-2015/579. (2015).

[16] K.G. Field, M.N. Gussev, Y. Yamamoto, X. Hu, R.H. Howard, Preliminary Studies on the Fabrication and Characterization of Fe-Cr-Al Alloys Designed to Have Enhanced Weldability and Radiation Tolerance, ORNL/TM-2015/192. (2015).

[17] K.G. Field, M.N. Gussev, R. Howard, First Annual Progress Report on Radiation Tolerance of Controlled Fusion Welds in High Temperature Oxidation Resistant FeCrAl Alloys, ORNL/TM2015/770. (2015).

[18] K.G. Field, R.H. Howard, Y. Yamamoto, Design of Experiment for Irradiation of Welded Candidate Fe-Cr-Al Alloys, ORNL/TM-2015/375. (2015).

[19] M.N. Gussev, K.G. Field, S.A. Briggs, Y. Yamamoto, Preliminary analysis of the general performance and mechanical behavior of irradiated $\mathrm{FeCrAl}$ base alloys and weldments, ORNL/TM-2016/552. (2016).

[20] K.G. Field, M.N. Gussev, Y. Yamamoto, L.L. Snead, Deformation behavior of laser welds in high temperature oxidation resistant $\mathrm{Fe}-\mathrm{Cr}-\mathrm{Al}$ alloys for fuel cladding applications, J. Nucl. Mater. 454 (2014) 352-358. doi:10.1016/j.jnucmat.2014.08.013.

[21] S. Kobayashi, T. Takasugi, Mapping of $475^{\circ} \mathrm{C}$ embrittlement in ferritic $\mathrm{Fe}-\mathrm{Cr}-\mathrm{Al}$ alloys, Scr. Mater. 63 (2010) 1104-1107. doi:10.1016/j.scriptamat.2010.08.015.

[22] K.G. Field, X. Hu, K.C. Littrell, Y. Yamamoto, L.L. Snead, Radiation tolerance of neutronirradiated model Fe-Cr-Al alloys, J. Nucl. Mater. 465 (2015) 746-755.

doi:10.1016/j.jnucmat.2015.06.023.

[23] P.D. Edmondson, S.A. Briggs, Y.Yamamoto, R.H. Howard, K. Sridharan, K.A. Terrani, et al., Irradiation-enhanced $\alpha^{\prime}$ precipitation in model FeCrAl alloys, Scr. Mater. 116 (2016) 112-116. doi:10.1016/j.scriptamat.2016.02.002.

[24] J.J. Heger, 885F embrittlement of the ferritic chromium-iron alloys, Met. Prog. (1951) 55-61.

[25] C. Capdevila, M.K. Miller, G. Pimentel, J. Chao, Influence of recrystallization on phase separation kinetics of oxide dispersion strengthened Fe-Cr-Al alloy, Scr. Mater. 66 (2012) 254-257. doi:10.1016/j.scriptamat.2011.11.003.

[26] M. Courtnall, F. Pickering, The effect of alloying on 485 C embrittlement, Met. Sci. 10 (1976) 273-276.

[27] E.A. Little, Neutron-irradiation hardening in irons and ferritic steels, Int. Met. Rev. 21 (1976) 2559.

[28] M. Bachhav, G. Robert Odette, E.A. Marquis, $\alpha^{\prime}$ precipitation in neutron-irradiated Fe-Cr alloys, Scr. Mater. 74 (2014) 48-51. doi:10.1016/j.scriptamat.2013.10.001.

[29] J. Lim, I.S. Hwang, J.H. Kim, Design of alumina forming FeCrAl steels for lead or lead-bismuth cooled fast reactors, J. Nucl. Mater. 441 (2013) 650-660. doi:10.1016/j.jnucmat.2012.04.006.

[30] M. Turski, M.C. Smith, P.J. Bouchard, L. Edwards, P.J. Withers, Spatially Resolved Materials Property Data From a Uniaxial Cross-Weld Tensile Test, J. Press. Vessel Technol. 131 (2009). 
[31] C. Leitão, I. Galvão, R.M. Leal, D.M. Rodrigues, Determination of local constitutive properties of aluminium friction stir welds using digital image correlation, Mater. Des. 33 (2012) 69-74. doi:10.1016/j.matdes.2011.07.009.

[32] M.O. Acar, Gungor, Salih, Experimental and numerical study of strength mismatch in cross-weld tensile testing How to cite, (n.d.). doi:10.1177/0309324715593699.

[33] M.N. Gussev, T.S. Byun, J.T. Busby, Description of strain hardening behavior in neutronirradiated fcc metals, J. Nucl. Mater. 427 (2012) 62-68. doi:10.1016/j.jnucmat.2012.04.017.

[34] A. Patra, D.L. McDowell, Crystal plasticity investigation of the microstructural factors influencing dislocation channeling in a model irradiated bcc material, Acta Mater. 110 (2016) 364-376. doi:10.1016/j.actamat.2016.03.041.

[35] M.N. Gussev, J.T. Busby, K.G. Field, M.A. Sokolov, S.E. Gray, Role of Scale Factor During Tensile Testing of Small Specimens, (2014) 1-19. doi:10.1520/stp157620140013.

[36] A. Hishinuma, A. Kohyama, R. Klueh, D. Gelles, W. Dietz, K. Ehrlich, Current status and future R\&D for reduced-activation ferritic/martensitic steels, J. Nucl. Mater. 258-263 (1998) 193-204.

[37] C.M. Parish, N.K. Kumar, L.L. Snead, P.D. Edmondson, K.G. Field, C. Silva, et al., LAMDA: Irradiated-Materials Microscopy at Oak Ridge National Laboratory, Microsc. Microanal. 21 (2015) 1003-1004. doi:10.1017/S1431927615005814. 